\title{
Serum amyloid A impairs the antiinflammatory properties of HDL
}

\author{
Chang Yeop Han, ${ }^{1}$ Chongren Tang, ${ }^{1}$ Myriam E. Guevara, ${ }^{2}$ Hao Wei, ${ }^{1}$ Tomasz Wietecha, ${ }^{3}$ Baohai Shao, ${ }^{1}$ Savitha Subramanian, ${ }^{1}$ \\ Mohamed Omer, ${ }^{1}$ Shari Wang, ${ }^{1}$ Kevin D. O'Brien, ${ }^{3}$ Santica M. Marcovina, ${ }^{1}$ Thomas N. Wight, ${ }^{4}$ Tomas Vaisar, ${ }^{1}$ Maria C. de Beer, ${ }^{5}$ \\ Frederick C. de Beer, ${ }^{6}$ William R. Osborne, ${ }^{7}$ Keith B. Elkon, ${ }^{2}$ and Alan Chait ${ }^{1}$
}

'Department of Medicine, Division of Metabolism, Endocrinology, and Nutrition, Diabetes and Obesity Center of Excellence, ${ }^{2}$ Division of Rheumatology, and ${ }^{3}$ Division of Cardiology, University of Washington, Seattle, Washington, USA. “Matrix Biology Program, Benaroya Research Institute, Seattle, Washington, USA. ${ }^{5}$ Department of Physiology and ${ }^{6}$ College of Medicine, University of Kentucky, Lexington, Kentucky, USA. 'Department of Pediatrics, University of Washington, Seattle, Washington, USA.

\begin{abstract}
HDL from healthy humans and lean mice inhibits palmitate-induced adipocyte inflammation; however, the effect of the inflammatory state on the functional properties of HDL on adipocytes is unknown. Here, we found that HDL from mice injected with $\mathrm{AgNO}_{3}$ fails to inhibit palmitate-induced inflammation and reduces cholesterol efflux from 3T3-L1 adipocytes. Moreover, HDL isolated from obese mice with moderate inflammation and humans with systemic lupus erythematosus had similar effects. Since serum amyloid A (SAA) concentrations in HDL increase with inflammation, we investigated whether elevated SAA is a causal factor in HDL dysfunction. $\mathrm{HDL}$ from $\mathrm{AgNO}_{3}$-injected mice lacking Saa1.1 and Saa2.1 exhibited a partial restoration of antiinflammatory and cholesterol efflux properties in adipocytes. Conversely, incorporation of SAA into

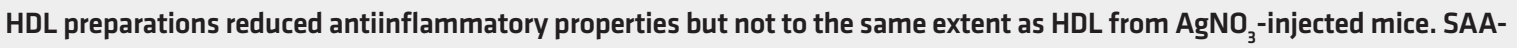
enriched HDL colocalized with cell surface-associated extracellular matrix (ECM) of adipocytes, suggesting impaired access to the plasma membrane. Enzymatic digestion of proteoglycans in the ECM restored the ability of SAA-containing HDL to inhibit palmitate-induced inflammation and cholesterol efflux. Collectively, these findings indicate that inflammation results in a loss of the antiinflammatory properties of HDL on adipocytes, which appears to partially result from the SAA component of HDL binding to cell-surface proteoglycans, thereby preventing access of HDL to the plasma membrane.
\end{abstract}

\section{Introduction}

HDL-cholesterol levels are reduced in obesity, especially in those individuals with features of the metabolic syndrome $(1,2)$. The metabolic syndrome is accompanied by adipose tissue (AT) $(3,4)$ and systemic inflammation (5). Because HDL-cholesterol levels can drop following acute inflammatory stimuli (6), it has been suggested that low HDL cholesterol levels associated with obesity are a result of chronic, low-grade inflammation (6). HDL has several functions, including mediation of reverse cholesterol transport (7) and inhibition of inflammation $(8-11)$, oxidation $(12,13)$, and endothelial activation $(14,15)$.

We recently showed that apolipoprotein A-I (apoA-I) and HDL derived from normal human subjects strongly inhibited palmitate-induced chemotactic factor expression in adipocytes in vitro and that overexpression of human apoA-I led to a reduction of macrophage accumulation and inflammatory gene expression in AT of mice fed a high-fat, proinflammatory diet (16). The ability of apoA-I and HDL to inhibit inflammation in adipocytes resulted

Conflict of interest: C. Tang and S. Wang have equity in health care-related publicly traded companies. K.D. O'Brien has received a grant from Sanofi. S.M. Marcovina is a consultant to Denka, Japan, and Medtest, USA; holds a patent for an assay for lipoprotein(a); and has received a grant from Inventive Health Clinical LLC. F.C. de Beer is an inventor and holds a patent entitled "Compositions and methods for detecting and treating atherosclerosis." K.B. Elkon has part ownership of a company called Resolve Therapeutics LLC. Submitted: July 1, 2015; Accepted: October 29, 2015.

Reference information: / Clin Invest. 2016;126(1):266-281. doi:10.1172/JCI83475. from disruption of lipid rafts (LRs) and reduction of plasma membrane cholesterol; it was also associated with a reduction in palmitate-induced generation of ROS (16).

HDL can become dysfunctional during inflammation (17-20). For example, HDL from acutely inflamed human subjects and rabbits (21), and from subjects with inflammatory disorders such as rheumatoid arthritis and systemic lupus erythematosus (SLE) (22), loses its antiinflammatory properties. Plasma levels of serum amyloid A (SAA) increase during acute and chronic inflammation (23). The SAA family of proteins are major acute-phase reactants in mammals (23). Circulating levels of the inducible forms of SAA, SAA1, and SAA2, which are produced mainly by the liver, increase dramatically after acute inflammatory stimuli (23). Since SAA1 and SAA2 are transported in plasma mainly on HDL (24-26), we investigated whether the presence of SAA on HDL affects its ability to inhibit palmitate-induced inflammation in adipocytes.

SAA-containing HDL has been shown to have reduced ability to facilitate cholesterol efflux from macrophages (26-29). The inability of HDL from patients with chronic renal failure to inhibit inflammation in smooth muscle cells has been attributed to the presence of SAA on HDL particles (30). HDL also might become dysfunctional due to oxidative damage. Myeloperoxidase (MPO) generates $\mathrm{HOCl}$, which oxidizes specific tyrosine and methionine residues on apoA-I, thereby impairing apoA-I-mediated cholesterol efflux (31-33). HDL has been proposed to become oxidized in the milieu of the artery wall (34-36) but might also be oxidized in AT (37-39). Although the presence of SAA on HDL has been reported to impair HDL's antioxi- 
dative functionality (40), little is known regarding the effect of HDL oxidation on its antiinflammatory properties.

The purpose of the present study was to determine whether HDL from inflamed mice and humans loses its ability to inhibit palmitate-induced inflammation and to facilitate cholesterol efflux in adipocytes, and if so, whether the increased content of SAA in HDL or oxidative damage of apoA-I accounts for these changes. Our findings demonstrate that HDL from (i) mice with silver nitrate-induced $\left(\mathrm{AgNO}_{3}\right.$-induced) acute inflammation, (ii) mice with obesity-induced chronic inflammation, and (iii) human subjects with inflammation and SLE were dysfunctional with respect to inhibition of palmitate-induced adipocyte inflammation, and that SAA could account for part of this impairment.

\section{Results}

$\mathrm{HDL}$ from $\mathrm{AgNO}_{3}$-injected mice exhibits reduced ability to inhibit both palmitate-induced adipocyte inflammation and ROS generation and to stimulate cholesterol efflux from adipocytes. We previously showed that apoA-I and HDL from normal human subjects disrupted LRs, reduced plasma membrane cholesterol content, and reduced palmitate-induced ROS generation and monocyte chemotactic factor expression in 3T3-L1 adipocytes (16). However, it is unknown whether these antiinflammatory properties are altered when the HDL is derived from subjects with evidence of systemic inflammation. To determine the effects of sterile inflammation on HDL function, we isolated HDL from C57BL/6 mice that had been injected with $\mathrm{AgNO}_{3} 24$ hours earlier. Although control HDL from PBS-injected mice blocked the increase of Saa3, Ccl2, Ill $\beta$, and Il6 gene expression induced by palmitate in a dose-dependent manner, this effect was lost when adipocytes were preexposed to HDL from $\mathrm{AgNO}_{3}$-injected mice (Figure $\left.1 \mathrm{~A}\right)$. $\mathrm{HDL}$ from $\mathrm{AgNO}_{3}$-injected mice also elicited reduced cholesterol efflux from adipocytes compared with control HDL (Figure 1B). To determine whether exposure of cells to HDL from $\mathrm{AgNO}_{3}$-injected mice disrupts LRs, LRs were visualized using Alexa Fluor 594 cholera toxin subunit $\beta$ (CTB), which selectively binds to LRs in the plasma membrane (41). Exposure of adipocytes to palmitate increased CTB-stained LRs compared with controls not exposed to palmitate, and preexposure to control HDL reduced LRs (Figure 1C). However, $\mathrm{HDL}$ from $\mathrm{AgNO}_{3}$-injected mice did not reduce palmitate-stimulated LRs to the same extent as control HDL (Figure 1C). Next, we evaluated whether HDL from $\mathrm{AgNO}_{3}$-injected mice affected palmitate-induced ROS generation. While control HDL suppressed palmitate-induced ROS generation, as described previously (16), $\mathrm{HDL}$ from $\mathrm{AgNO}_{3}$-injected mice did not block ROS generation (Figure 1D). We found similar results using other types of adipocytes, such as differentiated mouse embryonic fibroblasts (MEFs) and human adipocytes from subjects with the Simpson-Golabi-Behmel syndrome (SGBS), a rare X-linked disorder that can cause craniofacial, skeletal, cardiac, and renal abnormalities and is characterized by an increase in weight, height, or head circumference (ref. 42 and data not shown). Changes in the properties of HDL could not be accounted for by alteration of the lipoprotein's free cholesterol or phospholipid content, since these did not change after injection of $\mathrm{AgNO}_{3}$ (Supplemental Figure 1; supplemental material available online with this article; doi:10.1172/ JCI83475DS1). Moreover, removal of free cholesterol from HDL with methyl- $\beta$-cyclodextrin $(\mathrm{m} \beta \mathrm{CD}$ ) did not affect HDL's antiinflam- matory function (Supplemental Figure 1). To exclude the possibility that exposure of adipocytes to palmitate increased the phospholipid content of the plasma membrane, thereby acting as a sink for cholesterol, total phospholipid content of the adipocyte plasma membrane was measured and found to be unaltered by either palmitate or HDL exposure (Supplemental Figure 2). These results imply that HDL isolated from mice following an acute inflammatory stimulus loses its ability to facilitate cholesterol efflux, disrupt LRs, reduce the generation of palmitate-induced ROS, and inhibit palmitate-induced inflammatory gene expression.

SAA plays an important role in reducing the antiinflammatory effect of HDL. To investigate the effects of reducing levels of SAA in inflammatory $\mathrm{HDL}, \mathrm{HDL}$ was isolated from $\mathrm{AgNO}_{3}$-injected control $(\mathrm{C} 57 \mathrm{BL} / 6)$ and SAA-DKO $\left(\right.$ Saa1.1 $1^{-/} /$Saa.2.1 $\left.1^{-/}\right)$mice $(43,44)$. It has been reported that HDL isolated from inflamed SAA-DKO mice has trace amount of SAA (45) - presumably SAA4, the constitutive form of SAA - while inflamed HDL from C57BL/6 mice contains an abundance of SAA1.1 and SAA2.1 (45). In confirmation of these findings, we observed that the SAA protein concentrations in HDL from PBS- and $\mathrm{AgNO}_{3}$-injected C57BL/6 mice were $31 \pm 2 \mu \mathrm{g} / \mathrm{mg}$ and $362 \pm 35 \mu \mathrm{g} / \mathrm{mg}$ HDL protein $(n=6)$, respectively, whereas the SAA protein concentrations in $\mathrm{HDL}$ from $\mathrm{PBS}$ - and $\mathrm{AgNO}_{3}$-injected SAA-DKO mice were $24 \pm 2 \mu \mathrm{g} / \mathrm{mg}$ and $35 \pm 3 \mu \mathrm{g} / \mathrm{mg}$ HDL protein $(n=5)$, respectively. We first determined whether HDL from these 4 groups of mice could inhibit the expression of chemotactic factor and inflammatory genes in adipocytes subsequent to palmitate treatment. HDL from PBS-injected C57BL/6 and SAA-DKO mice inhibited palmitate-induced $S a a 3, C c l 2$, Il1 $\beta$, and $I l 6$ gene expression, whereas $\mathrm{HDL}$ from $\mathrm{AgNO}_{3}$-injected $\mathrm{C} 57 \mathrm{BL} / 6$ mice totally lost its inhibitory effect on palmitate-induced inflammatory gene expression. Importantly, $\mathrm{HDL}$ from $\mathrm{AgNO}_{3}$-injected SAA-DKO mice showed partial inhibition of palmitate-induced inflammatory gene expression (Figure 2A). Since the concentration of apoA-I as a percent of total HDL protein is reduced in HDL from $\mathrm{AgNO}_{3}^{-}$ injected C57BL/6 mice, we performed additional experiments in which more total HDL protein was added to provide equivalent amounts of apoA-I. These results showed the same pattern as when equal amounts of total HDL protein were added (data not shown). We also matched the concentration of HDL on the basis of particle number; the results showed the same pattern (data not shown).

HDL from PBS-injected C57BL/6 and SAA-DKO mice and HDL from $\mathrm{AgNO}_{3}$-injected SAA-DKO mice also decreased the cholesterol content of plasma membranes in 3T3-L1 adipocytes, whereas HDL from $\mathrm{AgNO}_{3}$-injected C57BL/6 mice did not (Figure 2B). Consistent with these effects on plasma membrane cholesterol levels, HDL from PBS-injected C57BL/6 and SAA-DKO mice, and HDL from $\mathrm{AgNO}_{3}$-injected SAA-DKO mice, increased cholesterol efflux (Figure $2 \mathrm{C}$ ). The ability of $\mathrm{HDL}$ from $\mathrm{AgNO}_{3}$-injected SAA-DKO mice to facilitate cholesterol efflux was restored, compared with HDL from $\mathrm{AgNO}_{3}$-injected C57BL/6 mice (Figure 2C). We previously have shown that inflammatory gene expression was inversely related to the content of LRs and to ROS generation and could be reversed by incubation with HDL from normal subjects (16). Therefore, we tested the effect of $\mathrm{HDL}$ from $\mathrm{AgNO}_{3}$-injected mice in this study. LRs and ROS generation were decreased by exposure of adipocytes to control HDL from PBS-injected C57BL/6 mice. Similar effects were observed with HDL from SAA-DKO mice. However, LRs and 
A
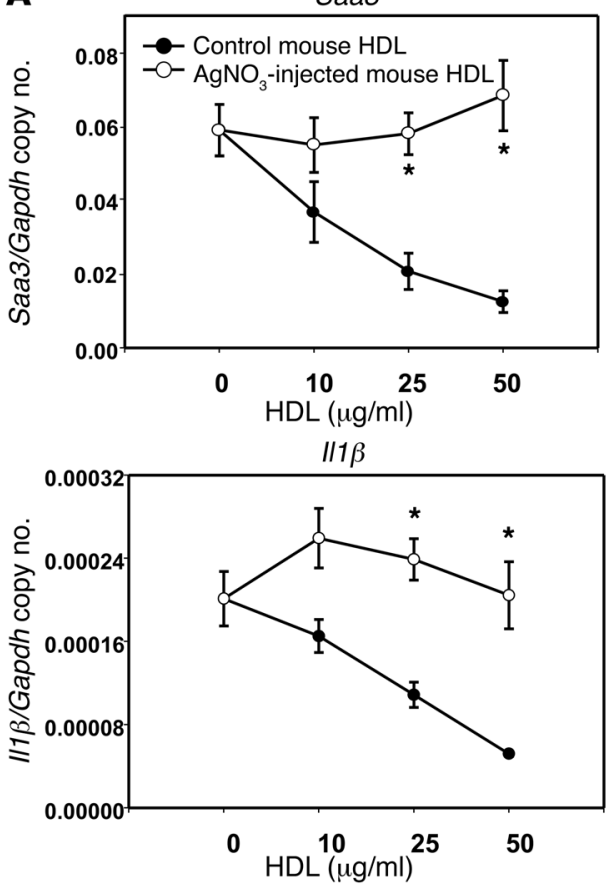

B

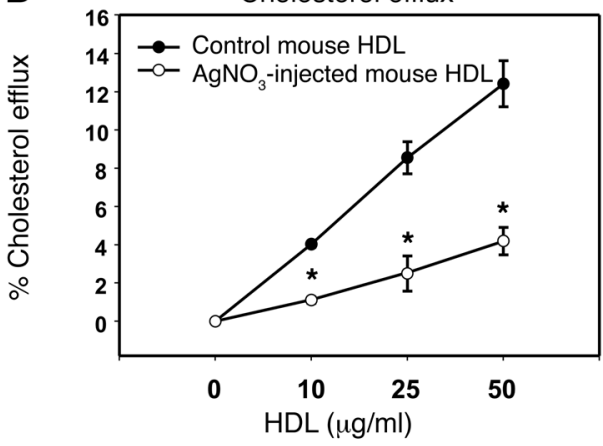

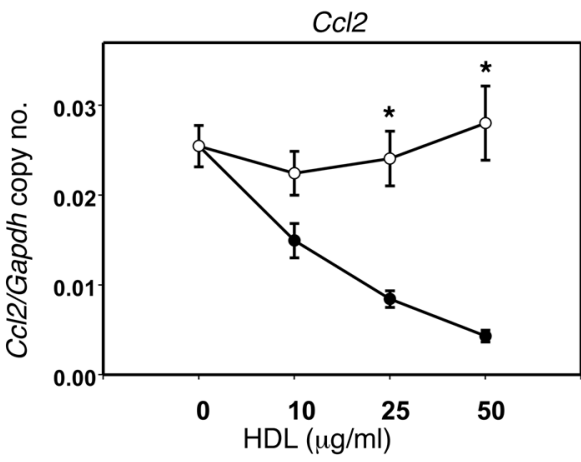

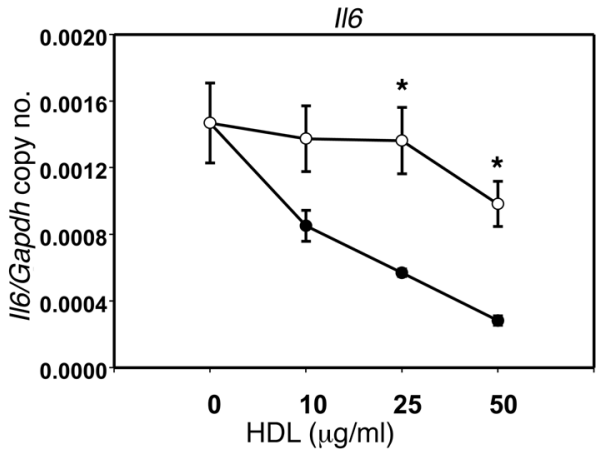

C
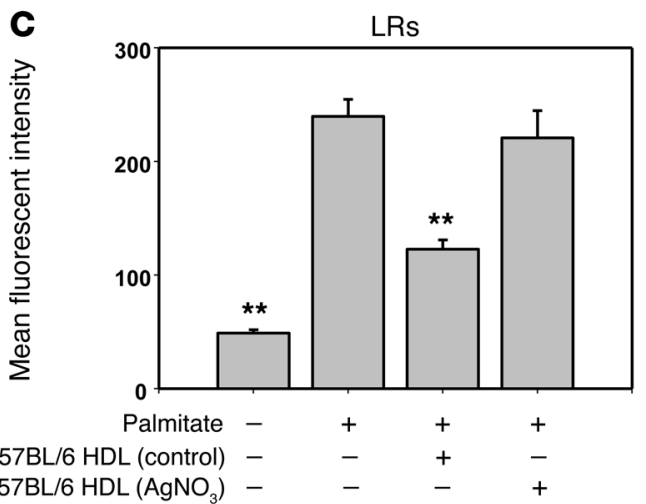

C57BL/6 HDL (control) - $\quad-\quad-\quad+\quad+$

Figure 1. $\mathrm{HDL}$ from $\mathrm{AgNO}_{3}$-injected mice loses its ability to inhibit palmitate-induced adipocyte inflammation, to stimulate cholesterol efflux, and to suppress ROS generation by adipocytes. (A-D) HDL was isolated from the plasma of $\mathrm{AgNO}_{3}$ - or PBS-injected C57BL/6 mice. 3T3-L1 adipocytes were preexposed to $\mathrm{HDL}$ (indicated concentration [A and B] or $50 \mu \mathrm{g}$ protein $/ \mathrm{ml}$ [C and $\mathbf{D}$ ]) for 6 hours, after which the HDL was removed, the cells were washed, and the adipocytes were incubated with or without palmitate $(250 \mu \mathrm{mol} / \mathrm{l})$ for 24 hours prior to measurement of Saa3, $\mathrm{Ccl} 2, \| 11 \beta$, and $/ 16$ gene expression (A), cholesterol efflux (B), LRs (C), and ROS generation (D) as described in Methods. Results are plotted as the mean fluorescent intensity of each sample on the vertical axis

(C and D). Data represent mean \pm SD. Data are representative of at least 3 independent experiments. ${ }^{*} P<0.001$ vs. control mouse $\mathrm{HDL}$, ${ }^{*} P<0.001$ vs. palmitate. ANOVA and Bonferroni post-hoc test.

D

ROS

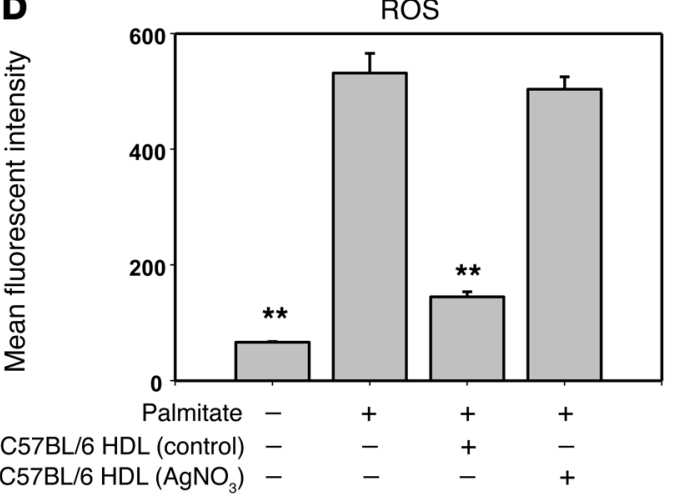

ROS generation were not inhibited by exposure of cells to HDL from $\mathrm{AgNO}_{3}$-injected $\mathrm{C} 57 \mathrm{BL} / 6$ mice, whereas $\mathrm{HDL}$ from $\mathrm{AgNO}_{3}$ injected SAA-DKO mice partially blocked LRs (Figure 2D) and ROS generation (Figure 2E). These results indicate that the absence of SAA in HDL from mice with sterile inflammation induced by the injection of $\mathrm{AgNO}_{3}$ causes a partial restoration of HDL's antiinflammatory properties on adipocytes.

Activation of TLR4 by LPS and certain free fatty acids can trigger cellular inflammatory responses $(46,47)$ and is accompanied by translocation of TLR4 into LRs (48). However, whether HDL can block this TLR4-mediated response is unknown. To investigate whether TLR4 translocation to LRs following exposure to palmitate could be inhibited by preexposure of adipocytes to HDL, and whether this would be affected by presence of SAA, we used HDL from $\mathrm{AgNO}_{3}$-injected C57BL/6 and SAA-DKO mice. Prior to exposure of adipocytes to palmitate, TLR4's presence was confined to non-LR fractions of the plasma membrane. Following palmitate exposure, TLR4 translocated from non-LR fractions to LR fractions 

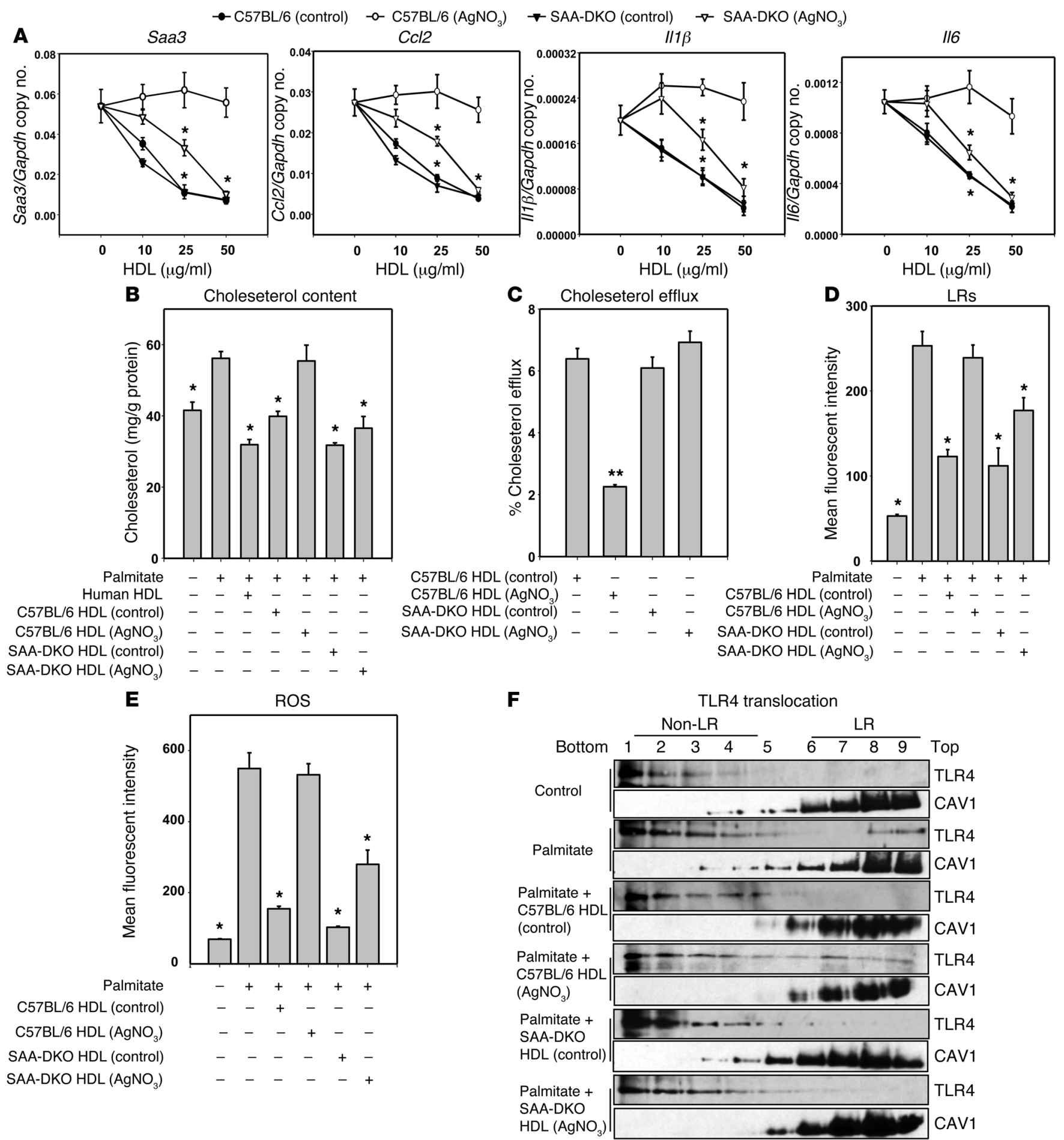

Figure 2. $\mathrm{HDL}$ from $\mathrm{AgNO}_{3}$-injected SAA-DKO mice retains part of its antiinflammatory effect on adipocytes. HDL was isolated from the plasma of $\mathrm{AgNO}_{3}$ - or PBS-injected C57BL/6 and SAA-DKO mice. 3T3-L1 adipocytes were treated as described in the legend to Figure 1. Saa3, Cc/2, II1 $\beta$, and II6 gene expression (A), plasma membrane cholesterol content (B), cholesterol efflux (C), LR content (D), ROS generation (E), and TLR4 translocation to LRs (F) were analyzed. An antibody to caveolin 1 (CAV1) was used to stain LRs. Fractions 7-9 contain LRs, and fractions 1 -4 are non-LR-containing fractions. Data represent mean $\pm \mathrm{SD}$. Data are representative of at least 3 independent experiments. ${ }^{*} P<0.001 \mathrm{vs}$. C57BL/6 ( $\left.\mathrm{AgNO} \mathrm{B}_{3}\right) \mathrm{HDL},{ }^{* *} P<0.001 \mathrm{vs}$. C57BL/6 (control) HDL. ANOVA and Bonferroni post-hoc test.

(Figure 2F, top 2 panels). This effect was inhibited by preexposure of the cells to HDL from PBS-injected C57BL/6 mice but not by preexposure to $\mathrm{HDL}$ from $\mathrm{AgNO}_{3}$-injected $\mathrm{C} 57 \mathrm{BL} / 6$ mice (Figure $2 \mathrm{~F}$, middle 2 panels). However, when cells were preexposed to HDL from $\mathrm{AgNO}_{3}$-injected SAA-DKO mice, TLR4 did not translocate to LR fractions following palmitate exposure (Figure 2F, bottom 2 panels). These results are consistent with the results of cholesterol efflux and LRs from $\mathrm{HDL}$ from $\mathrm{AgNO}_{3}$-injected SAA-DKO mice 

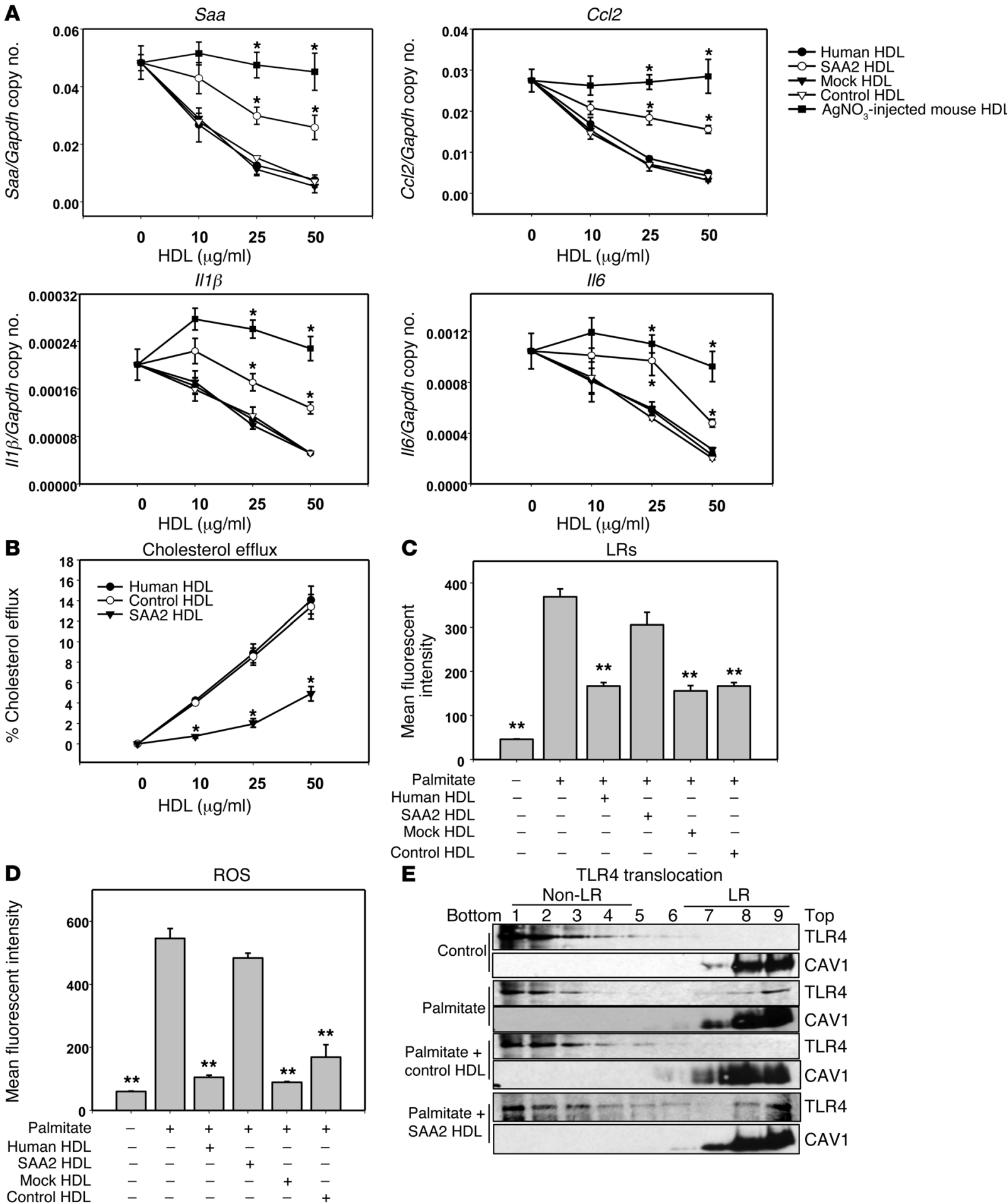

Figure 3. SAA-enriched HDL partly loses its antiinflammatory effect on adipocytes. (A-E) 3T3-L1 adipocytes were preexposed for 6 hours to human HDL or human HDL isolated after exposure to lentiviral-transduced $293 \mathrm{HEK}$ cells, as described in Methods. HDL concentration was as indicated (A and B) or 50 $\mu \mathrm{g}$ protein $/ \mathrm{ml}$ (C and $\mathbf{D})$. Thereafter, adipocytes were treated as described in the legend to Figure 1. Saa3, Ccl2, II1 $\beta$, and I/6 gene expression (A); cholesterol efflux to human, control, and SAA2-HDL (B); LR content (C); ROS generation (D); and TLR4 translocation to LRs (E). An antibody to caveolin 1 (CAV1) was used to stain LRs. Fractions 7-9 contain LRs, and fractions 1-4 are non-LR-containing fractions. Data represent mean \pm SD. Data are representative of at least 3 independent experiments. ${ }^{*} P<0.001$ vs. control-HDL, ${ }^{* *} P<0.001$ vs. SAA2-HDL. ANOVA and Bonferroni post-hoc test. 
A
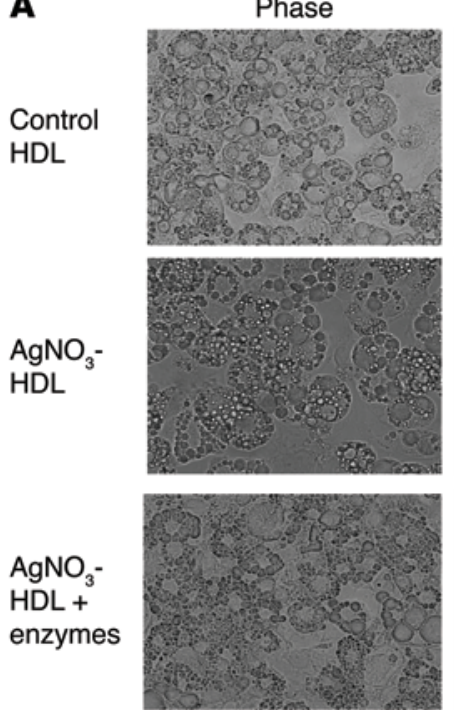

B
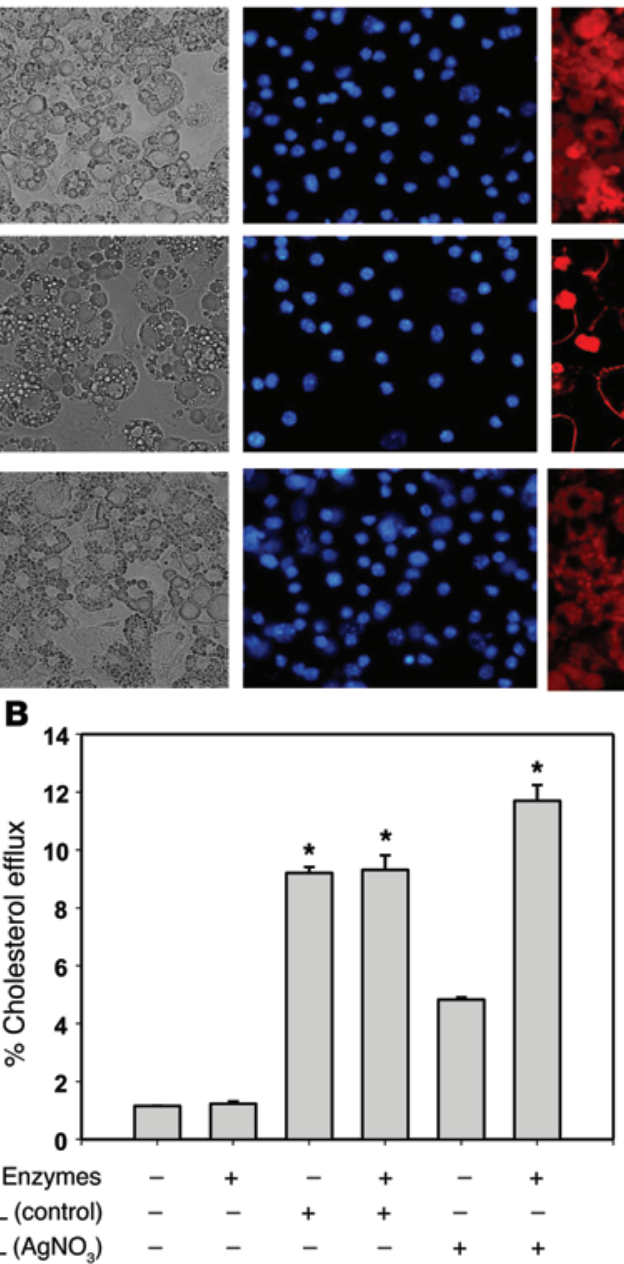

$+\infty, \infty$
Dil HDL
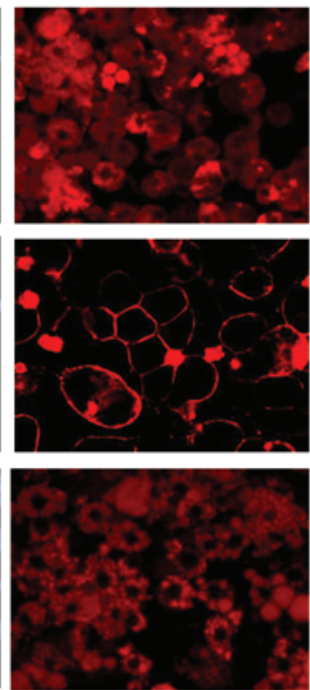

C

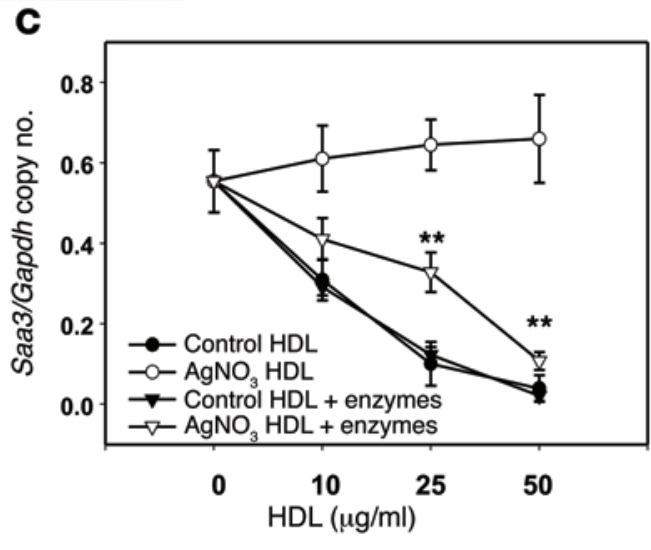

Figure 4. $\mathrm{HDL}$ from $\mathrm{AgNO}_{3}$-injected mice colocalizes with the adipocyte cell surface. (A) $\mathrm{HDL}$ from PBS- and $\mathrm{AgNO}_{3}$-injected $\mathrm{C} 57 \mathrm{BL} / 6$ mice was labeled with $\mathrm{Dil}$ (red). After exposure to these HDL preparations ( $50 \mu \mathrm{g}$ protein/ml) for 6 hours, 3T3-L1 adipocytes were fixed in $2 \%$ formalin for 5 minutes. To distinguish the outside of cells from intracellular sites, the cell surface-associated ECM was stained with Alexa Fluor 488-conjugated WGA (green). Cell nuclei were counterstained with DAPI (blue). Cell morphology was shown by phase-contrast photography (left panels). Merged fluorescence (overlay) is shown in yellow. Original magnification, $\times 400$. When the cell surface-associated ECM of 3T3-L1 adipocytes was digested with chondroitin ABC lyase and heparitinase for 1 hour prior to exposure to $\mathrm{HDL}$, colocalization of $\mathrm{HDL}$ from $\mathrm{AgNO}_{3}$-injected mice with the cell surface (row 2, column 5) was lost and resulted in a similar distribution of dye to that seen with control HDL (row 3, column 5). (B and C) Enzyme digestion of the proteoglycans in the ECM also restored the impaired cholesterol efflux observed with $\mathrm{HDL}$ from $\mathrm{AgNO}_{3}$-injected mice (B) and Saa3 gene expression (C). Representative fluorescence images of 3 independent experiments are shown. Data represent mean \pm SD. Data are representative of at least 3 independent experiments. ${ }^{*} P<0.001$ vs. C57BL/6 HDL $\left(\mathrm{AgNO}_{3}\right)$, ${ }^{* *} \mathrm{P}<0.001 \mathrm{vs} . \mathrm{AgNO}_{3}-\mathrm{HDL}$. ANOVA and Bonferroni post-hoc test.

and indicate that the absence of SAA in HDL from mice with sterile inflammation induced by $\mathrm{AgNO}_{3}$ injection causes a partial restoration of HDL's antiinflammatory properties on adipocytes.

Conversely, to test whether increasing the SAA content in HDL would have the opposite effect, we incorporated mouse SAA2.1 into HDL by exposing normal human HDL to HEK 293 cells transduced with a lentivirus encoding mouse SAA2.1 protein. After exposure of HDL to these cells for 24 hours, HDL was reisolated from the conditioned media and had a strong SAA band visible on SDS-PAGE, compared with several control HDL preparations (Supplemental Figure 3). This reisolated HDL preparation (termed SAA2-HDL) had $145 \pm 5 \mu \mathrm{g} \mathrm{SAA} / \mathrm{mg}$ HDL protein $(n=5)$; all other HDL controls had no measurable SAA. Reisolated HDL that was exposed to HEK 293 cells alone without lentiviral transduction (control HDL), reisolated HDL that was exposed to mock-transduced HEK 293 cells (mock-HDL), and normal human HDL all inhibited palmitateinduced Saa3, Ccl2, Il1 $\beta$, and $I l 6$ gene expression (Figure 3A). However, SAA2-HDL partially lost its ability to inhibit palmitate-induced inflammatory gene expression, although the loss of inhibition was not as great as for $\mathrm{HDL}$ from $\mathrm{AgNO}_{3}$-injected C57BL/6 mice (Figure $3 \mathrm{~A})$. Also, human HDL and control HDL dose-dependently increased cholesterol efflux, while SAA2-HDL elicited less cholesterol efflux (Figure 3B). Consistent with the findings with inflammatory gene expression, LRs (Figure $3 \mathrm{C}$ ) and ROS generation (Figure 3D) were decreased by all 3 control HDL preparations relative to palmitate alone, while SAA2-HDL partially blocked CTB-stained LRs (Figure 3C) and ROS generation (Figure 3D).

To investigate the effect of increasing SAA in control HDL on TLR4, we used HDL that had been enriched in its content of SAA (SAA2-HDL). Following palmitate exposure, TLR4 translocated 


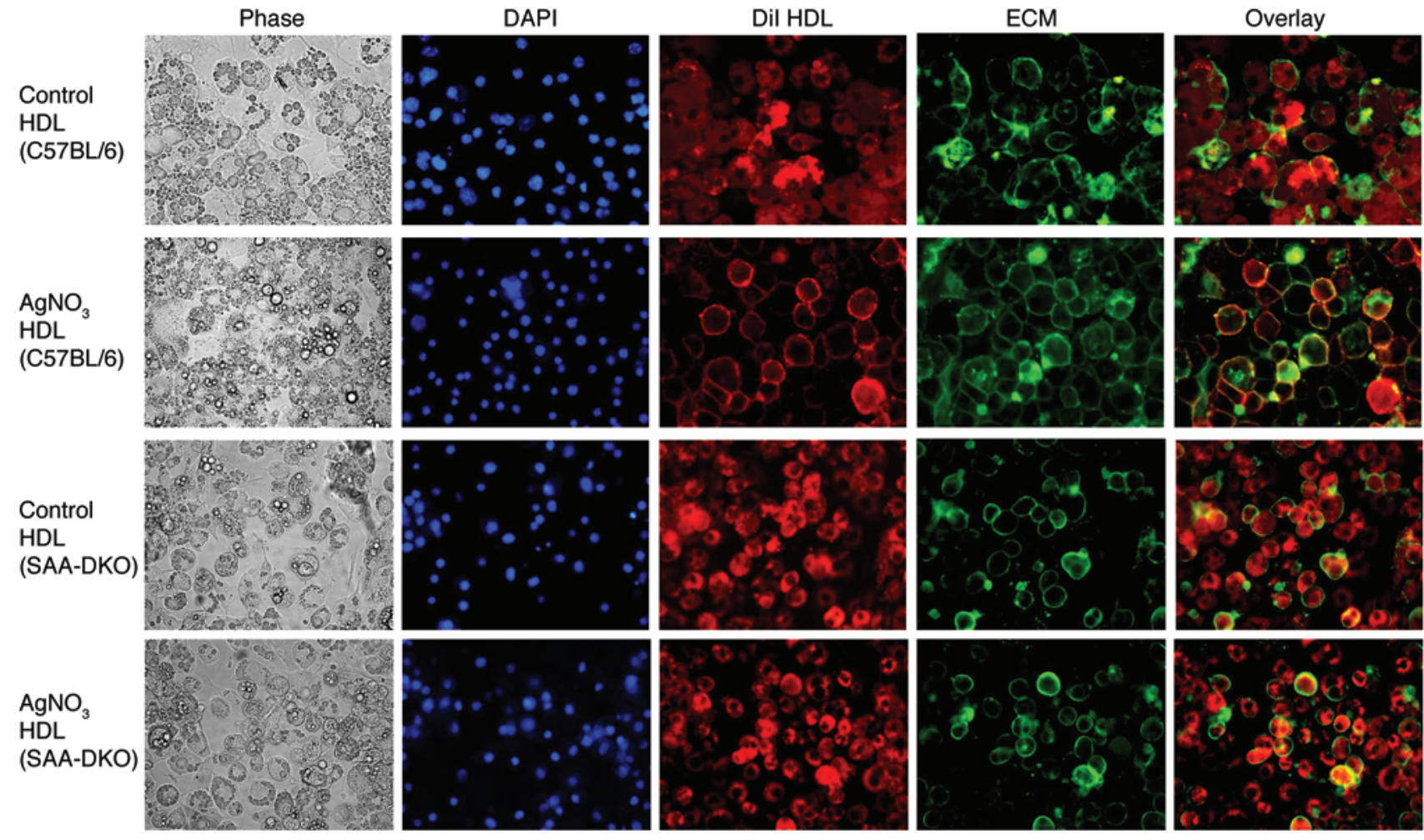

Figure 5. $\mathrm{HDL}$ from $\mathrm{AgNO}_{3}$-injected SAA-DKO mice does not colocalize with the adipocyte cell surface, while $\mathrm{HDL}$ from $\mathrm{AgNO}_{3}$-injected C57BL/6 mice does. $\mathrm{HDL}$ from PBS- and $\mathrm{AgNO}_{3}$-injected C57BL/6 and SAA-DKO mice was labeled with Dil (red). 3T3-L1 adipocytes were exposed to these HDL preparations as described in the legend to Figure 4. Original magnification, $\times 400$. HDL from $\mathrm{AgNO}_{3}$-injected SAA-DKO mice exhibited much less colocalization with the adipocyte cell surface than $\mathrm{HDL}$ from $\mathrm{AgNO}_{3}$-injected C57BL/6 mice. Representative fluorescence images of 3 independent experiments are shown.

from non-LR to LR fractions (Figure 3E, top 2 panels). This effect was inhibited by preexposure of the cells to control HDL but was restored by exposure to SAA2-HDL (Figure 3E, bottom 2 panels). These results indicate that loading SAA into HDL causes a partial loss of HDL's antiinflammatory effect on adipocytes, consistent with changes in translocation of TLR4 to the LR fractions in the plasma membrane.

Since we hypothesized that the increased SAA content in HDL impairs its antiinflammatory function, we investigated whether HDL antiinflammatory function was restored as SAA concentration returned to baseline following the injection of $\mathrm{AgNO}_{3}$. HDL's ability to inhibit palmitate-induced inflammatory gene expression was partially restored 96 hours after $\mathrm{AgNO}_{3}$ injection and fully restored by 7 days, consistent with changes in its SAA content (Supplemental Figure 4).

The presence of SAA on HDL blocks its access to the adipocyte cell membrane. We previously have shown that the presence of SAA in HDL enhances its ability to bind to biglycan (49) and that apoA-I and SAA are colocalized in the extracellular matrix (ECM) of atherosclerosis lesion (50). Moreover, we also have shown that adipocytes produce large amounts of ECM when they become hypertrophic (51). Therefore, it is plausible that the presence of SAA in HDL could cause the lipoprotein to bind to the ECM of adipocytes. To explore potential mechanisms by which SAA impairs the antiinflammatory properties of HDL, we tested the hypothesis that the presence of SAA in HDL particles facilitates trapping of HDL by cell surface-associated ECM, thereby limiting its ability to facilitate cholesterol efflux and any downstream effects. For these experiments, we stained HDL with 1,1'-dioctadecyl-3,3,3',3'tetramethylindocarbocyanine perchlorate (DiI) and the cell surface-associated ECM with wheat germ agglutinin (WGA). After exposure of adipocytes to DiI-stained control HDL, the cytosol was stained with DiI, which did not colocalize with the Alexa Fluor 488-WGA ECM staining (Figure 4A, top row). It is known that cholesterol and other lipids can transfer between HDL and cells in a bidirectional manner, mediated by the scavenger receptor B-I (SRB-I) or by simple diffusion $(52,53)$. This is consistent with our finding that DiI from control HDL can contact the plasma membrane and enter the cytosol of adipocytes. On the contrary, after exposure of cells to $\mathrm{HDL}$ labeled with $\mathrm{DiI}$ from $\mathrm{AgNO}_{3}$-injected mice, the DiI staining colocalizes with cell surface-associated ECM staining (Figure 4A, middle row). This suggests that HDL labeled with DiI from $\mathrm{AgNO}_{3}$-injected mice can be trapped in the cell surface-associated ECM of adipocytes and not be able to adequately contact the plasma membrane. Digestion of the ECM with chondroitin $\mathrm{ABC}$ lyase and heparitinase resulted in reversion of the staining pattern for $\mathrm{HDL}$ from the $\mathrm{AgNO}_{3}$-injected mice to that seen with control HDL (Figure 4A, lower row). This suggests that removal of proteoglycans from the cell surface-associated ECM allows $\mathrm{HDL}$ from $\mathrm{AgNO}_{3}$-injected mice to contact the plasma membrane. Digestion of the ECM with chondroitin ABC lyase and heparitinase also restored the ability of $\mathrm{HDL}$ from $\mathrm{AgNO}_{3}$-injected mice to mediate cholesterol efflux (Figure 4B) and to inhibit Saa3 gene expression (Figure 4C). 
A

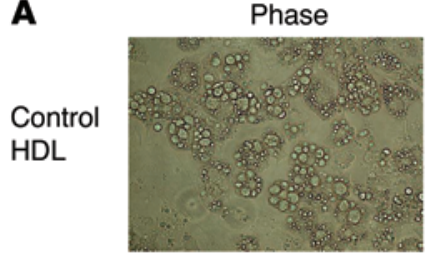

SAA2 HDL

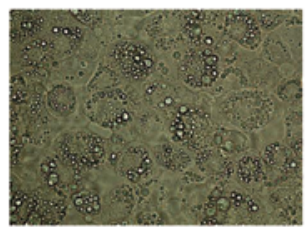

SAA2

$\mathrm{HDL}+$ enzymes

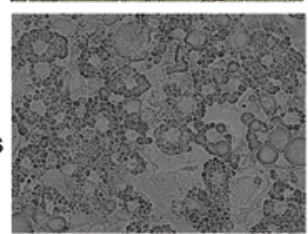

B

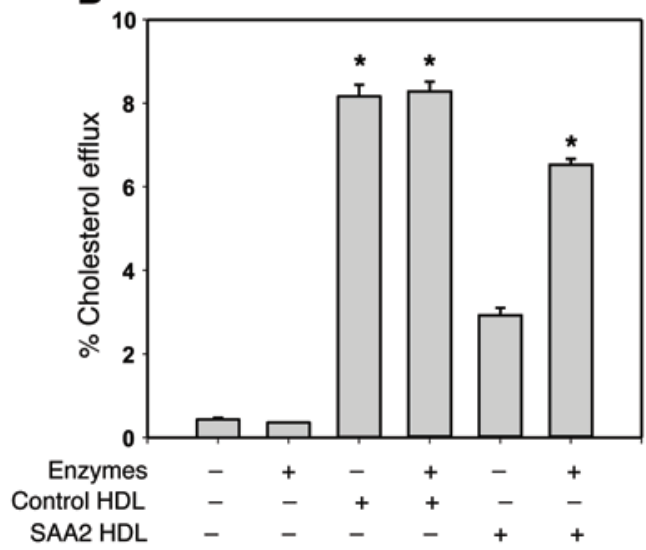

DAPI
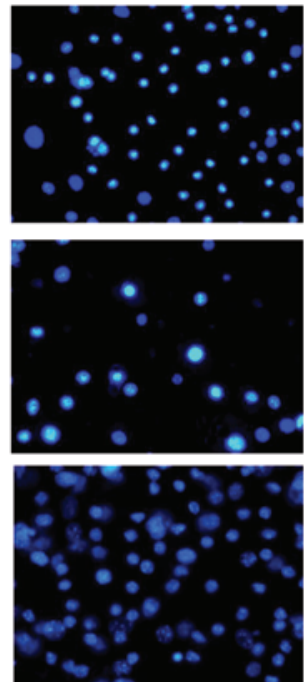

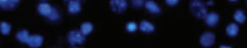

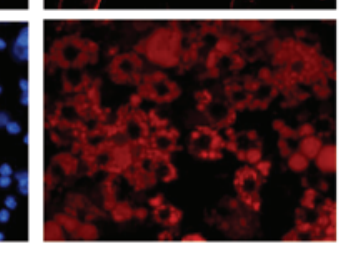

C

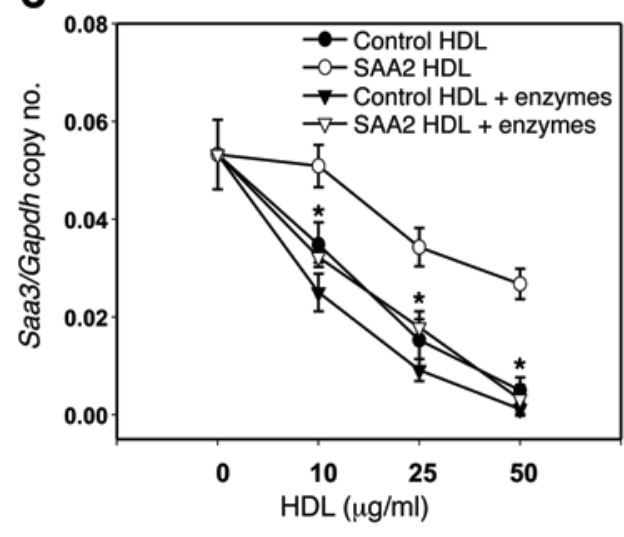

Figure 6. SAA-enriched HDL colocalizes with the adipocyte cell surface. (A) Control HDL, which was reisolated from conditioned media from cells not transduced with lentivirus, and SAA2-HDL, which was reisolated from conditioned media from cells transduced with a lentivirus-encoding mouse SAA2.1 protein were labeled with Dil (red). 3T3-L1 adipocytes were exposed to these HDL preparations and stained as described in the legend to Figure 4. Original magnification, $\times 400$. SAA2-HDL colocalized with cell surface-associated ECM staining. Pretreatment of adipocytes with chondroitin ABC lyase and heparitinase prior to exposure of SAA2-HDL resulted in a similar distribution of dye to that seen with control HDL. (B and C) Representative fluorescence images of 3 independent experiments are shown. After predigestion of the proteoglycans of 3T3-L1 adipocytes with chondroitin ABC lyase and heparitinase for 1 hour, exposure to SAA2-HDL (50 $\mu \mathrm{g}$ protein/ml) for 6 hours resulted in a restoration of cholesterol efflux (B) and Saa3 gene expression (C) toward that seen with control HDL. Data represent mean \pm SD. Data are representative of at least 3 independent experiments. ${ }^{*} P<0.001 \mathrm{vs}$. SAA2-HDL. ANOVA and Bonferroni post-hoc test.

HDL labeled with DiI from $\mathrm{AgNO}_{3}$-injected SAA-DKO mice showed a different pattern of staining. Similar to control HDL from PBS-injected C57BL/6 and SAA-DKO mice (Figure 5, first and third row), HDL labeled with DiI from $\mathrm{AgNO}_{3}$-injected SAADKO mice showed no colocalization with cell surface-associated ECM (Figure 5, fourth row), whereas HDL labeled with DiI from $\mathrm{AgNO}_{3}$-injected C57BL/6 mice colocalized with cell surface-associated ECM (Figure 5, second row). This suggests that the absence of SAA in HDL from $\mathrm{AgNO}_{3}$-injected mice prevents the HDL from binding to proteoglycans associated with the cell surface. The DiI in HDL that is devoid of SAA is thus able to directly contact the plasma membrane of adipocytes and enter the cytoplasm.

The pattern of staining of SAA2-HDL labeled with DiI more closely resembled that seen in HDL labeled with DiI from $\mathrm{AgNO}_{3}$-injected $\mathrm{C} 57 \mathrm{BL} / 6$ mice, both before and after enzyme digestion (Figure 6A, second and third row). This suggests that enriching HDL with SAA allows the lipoprotein to be trapped at the adipocyte cell surface and prevents the Dil from entering cells. Prior digestion of proteoglycans in the adipocyte matrix restored the ability of SAA2-HDL to mediate cholesterol efflux (Figure 6B) and to inhibit Saa3 gene expression (Figure 6C). These enzymes could potentially digest cell surface receptors and thereby affect palmitate-induced cell signaling. However, treatment of adipocytes with these enzymes did not affect palmitate-induced inflammatory gene expression (Supplemental Figure 5A). Subsequent experiments with either chondroitin $\mathrm{ABC}$ lyase or heparitinase alone indicated that digestion of the matrix by chondroitinase, but not heparitinase, was responsible for this effect (Supplemental Figure 5B). Since 3T3-L1 adipocytes produce a hyaluronan-rich-associated ECM (51), we also digested the ECM with hyaluronidase. 

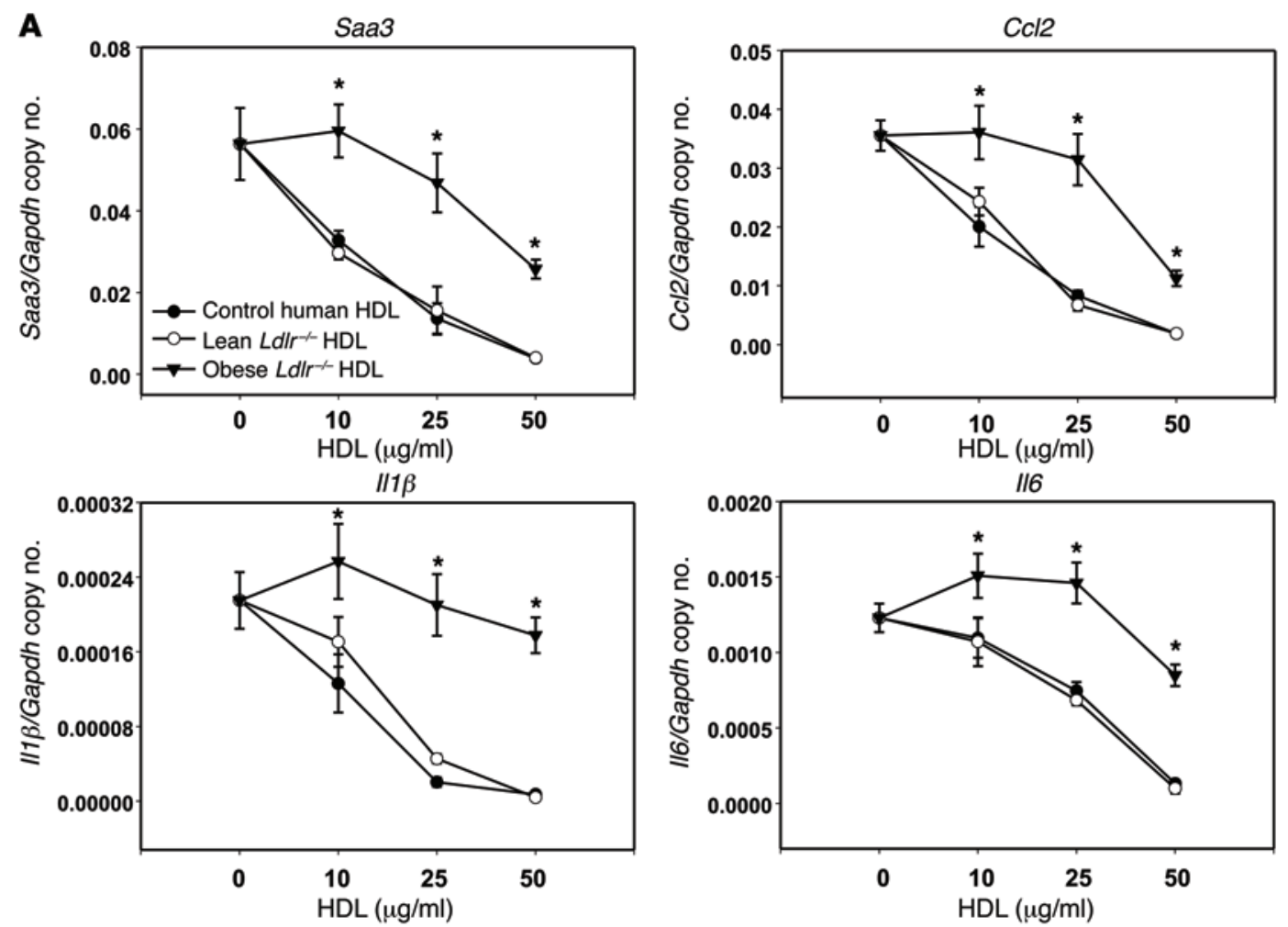

Figure 7. HDL from moderately inflamed obese mice loses its antiinflammatory effect on adipocytes and colocalizes with ECM in AT. (A) 3T3-L1 adipocytes were preexposed for 6 hours to the indicated concentrations of HDL, which was isolated from the plasma of $\mathrm{LdIr}^{-1}$ mice fed chow or HFHSC diets for 20 weeks $(n=5)$. After that, adipocytes were treated as per the legend to Figure 1 for measurement of Saa3, $C \mathrm{Cl} 2, \| 11 \beta$, and $/ / 6$ gene expression. (B) Epididymal fat isolated from $[57 \mathrm{BL} / 6$ mice fed chow or HFHSC diets for 20 weeks was stained with Movat's pentachrome stain and analyzed by IHC using anti-apoA-I and anti-SAA antibodies (B, $n=9)$. SAA colocalized with apoA-I in the ECM (blue stain with Movat's) of ATs from mice fed the HFHSC diet. Tissues were photographed

B

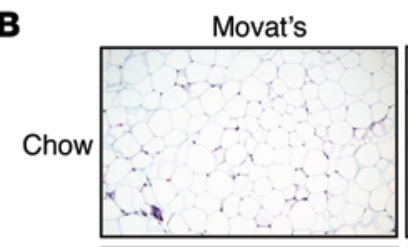

ApoA-I

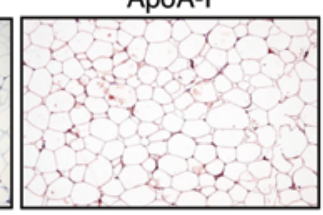

SAA
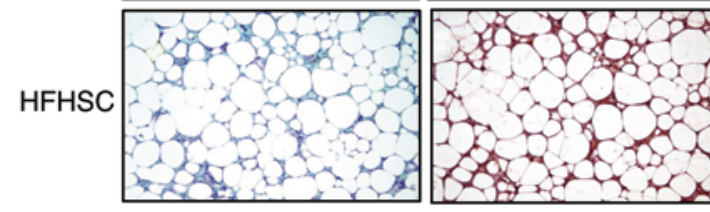
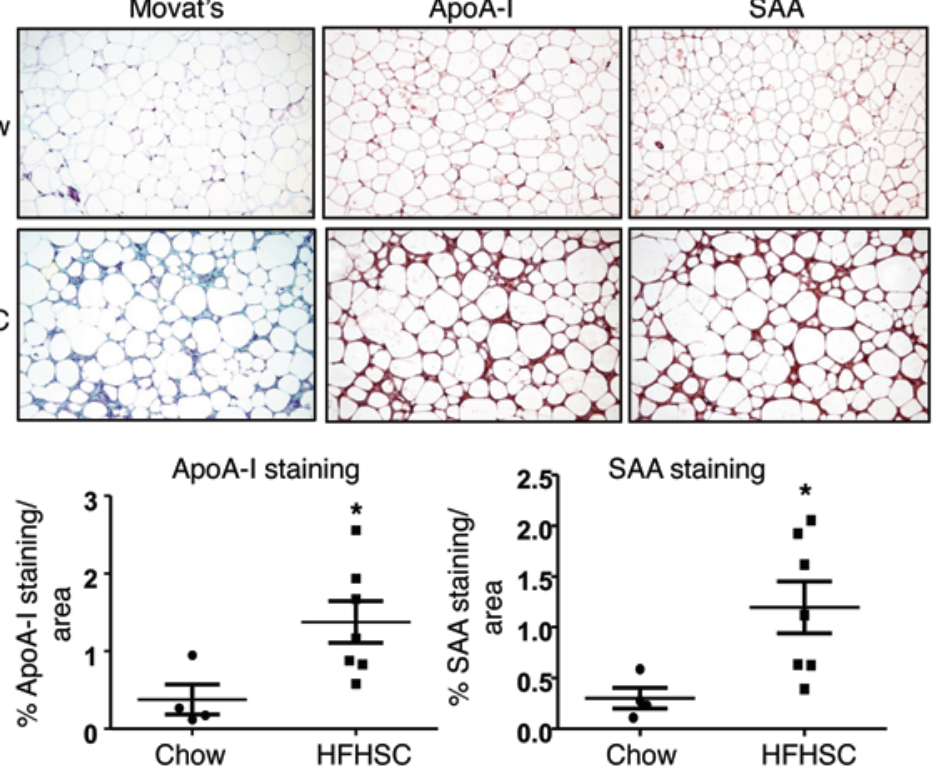

SAA staining
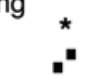

"
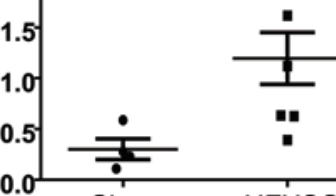

Chow HFHSC using microscopy. Original magnification, $\times 60$. Data represent mean \pm SD. ${ }^{*} P<0.001$ vs. chow. ANOVA and Bonferroni post-hoc test for $\mathbf{A}$, and Student $t$ test for $\mathbf{B}$.

Predigestion of the matrix with hyaluronidase also was shown not to be responsible for these effects (Supplemental Figure 5B). These results suggest that HDL containing SAA, which contains known proteoglycan binding domains $(23,49)$, binds to chondroitin-sulfate proteoglycans associated with the surface of adipocytes and may not be able to adequately contact the plasma membrane. This absence of contact could underlie the diminished capacity of SAAcontaining HDL to facilitate cholesterol efflux. The observation that colocalization was disrupted by enzymatic digestion of proteoglycans on the adipocyte cell surface before exposing cells to HDL labeled with DiI from $\mathrm{AgNO}_{3}$-injected C57BL/6 mice or SAA2HDL labeled with DiI provides further support for this notion.
To prevent SAA in HDL binding to the proteoglycans associated with the cell surface, we chemically modified the arginine and lysine residues of apolipoprotein in $\mathrm{HDL}$ from $\mathrm{AgNO}_{3}-$ injected mice. SAA1/2 have glycosaminoglycan binding domains (23). The negative charge of glycosaminoglycans in proteoglycans provides electrostatic attraction for cationic arginine and lysine residues in SAA. To test whether modification of arginine and lysine residues of SAA in HDL would inhibit HDL binding to the ECM of adipocytes, lysine and arginine groups in SAAcontaining $\mathrm{HDL}$ from $\mathrm{AgNO}_{3}$-injected mice were modified by reductive methylation and cyclohexanedione treatment, respectively. Modified DiI-labeled HDL from $\mathrm{AgNO}_{3}$-injected C57BL/6 
A

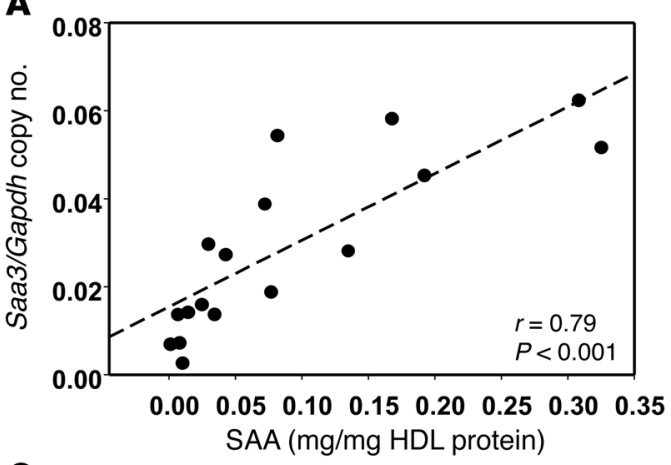

C

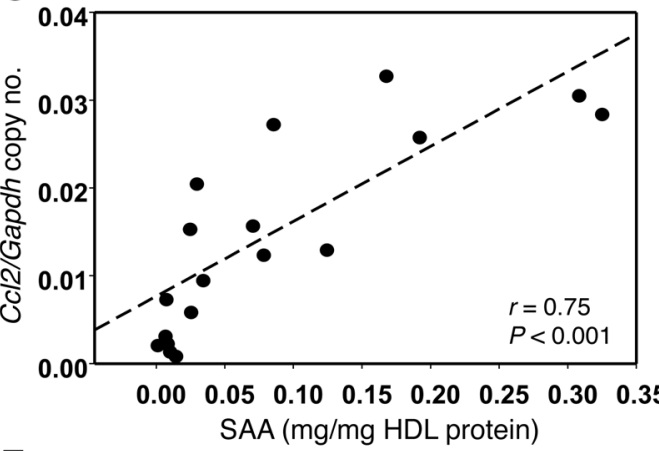

E

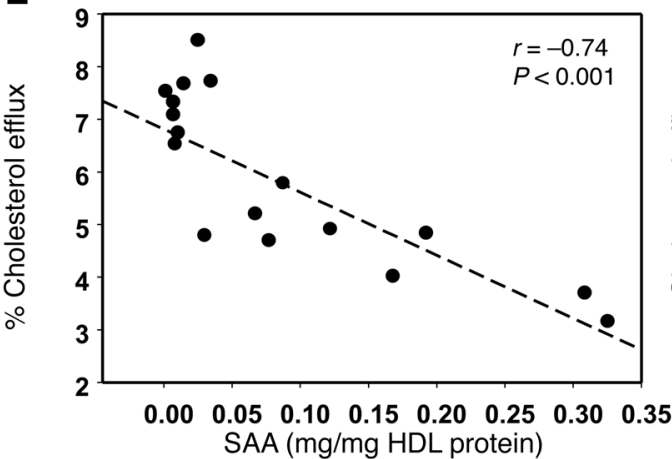

G

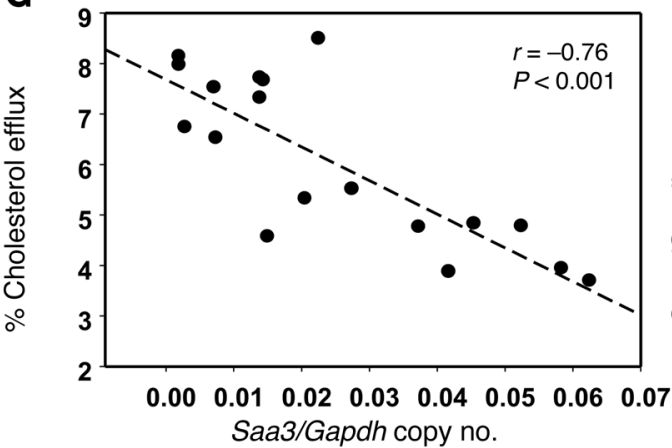

B

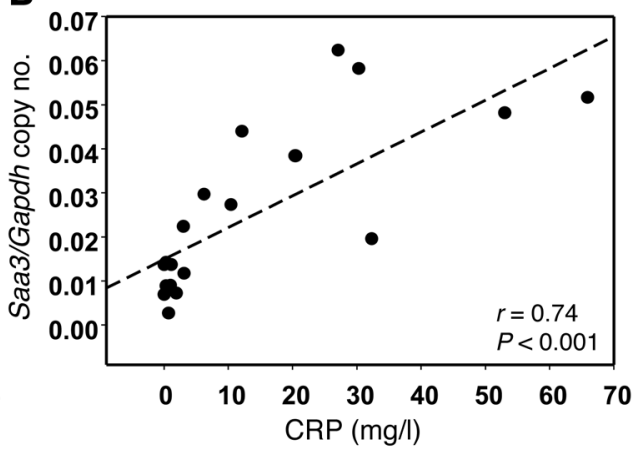

D

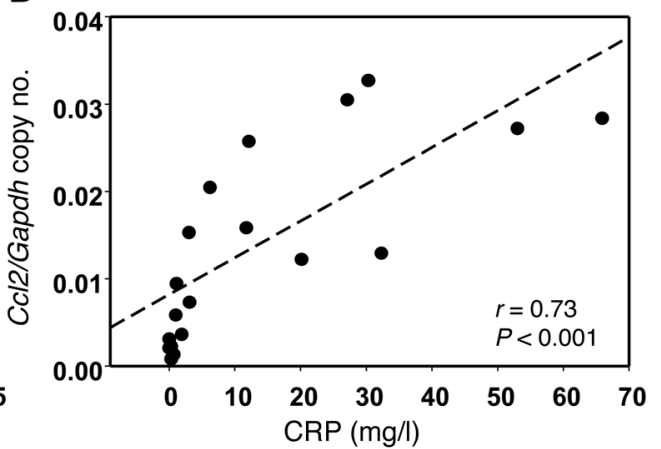

$\mathbf{F}$

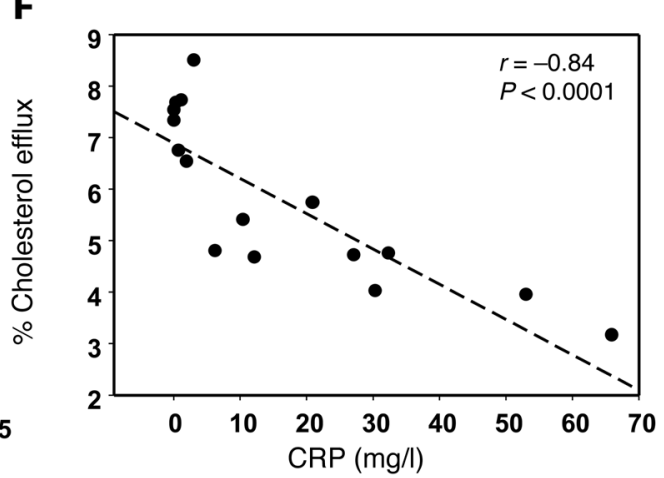

H

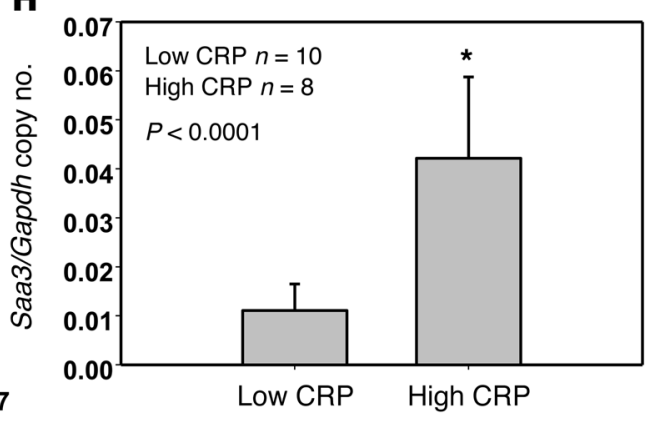

Figure 8. Loss of antiinflammatory effect on adipocytes of HDL from SLE patients with high CRP and SAA levels. (A-G) HDL was isolated from plasma of SLE patient $(n=18)$ and tested for their antiinflammatory effect on Saa3 and $\mathrm{Cc} / 2$ gene expression, as well as cholesterol efflux. Linear regression relationships among Saa3 and Ccl2 gene expression, plasma SAA, CRP levels, and percentage of cholesterol efflux were plotted using Pearson correlation coefficient. (H) Subjects were arbitrarily divided into those with lower ( $<10 \mathrm{mg} / \mathrm{l})$ and higher $(>10$ $\mathrm{mg} / \mathrm{I})$ CRP levels for comparison of their HDL to inhibit Saa3 gene expression. Data represent mean \pm SD. Student $t$ test mice showed reduced colocalization with cell surface-associated ECM (Supplemental Figure 6, second row), compared with unmodified DiI-labeled HDL from $\mathrm{AgNO}_{3}$-injected mice (Supplemental Figure 6, first row).

Collectively, these results imply that SAA in HDL plays an important role in reducing HDL's antiinflammatory function via blocking the access of HDL to the plasma membrane, thereby limiting cholesterol efflux and maintaining higher levels of LR cholesterol and TLR4 in these rafts.
Dysfunctional HDL is found in modestly inflamed obese mice and in human subjects with SLE and inflammation. To determine whether HDL isolated from subjects with more modest and pathophysiologically relevant degrees of inflammation also were impaired with respect to inhibition of palmitate-induced inflammatory gene expression in adipocytes, we chose to apply our findings to in vivo animal and human clinical situations. To this end, we studied HDL from obese mice fed a high-fat, high-sucrose, cholesterol-containing diet (HFHSC diet) that had evidence of both AT and systemic 
inflammation, and HDL from human subjects with SLE. HDL isolated from male mice fed a HFHSC diet for 20 weeks had high levels of SAA in their HDL compared with chow-fed control mice (26.2 $\pm 5.2 \mu \mathrm{g} / \mathrm{mg}$ vs. $175.5 \pm 43.8 \mu \mathrm{g} / \mathrm{mg}$ HDL protein, chow vs. HFHSC, $n=5)$. Control human HDL and HDL from control $\mathrm{Ldlr}^{-/}$mice were able to inhibit palmitate-induced inflammatory gene expression in 3T3-L1 adipocytes, while HDL from the obese HFHSC-fed animals lost its ability to block inflammatory gene expression (Figure 7A). However, the extent of oxidation of apoA-I, measured by mass spectrometry (MS) as chlorinated tyrosine and oxidized methionine, was not significantly changed between control HDL and HDL isolated from plasma of $\mathrm{AgNO}_{3}$-injected mice (chlorinated tyrosine $71-58 \pm 8 \mu \mathrm{mol} / \mathrm{mol}$ vs. $62 \pm 10 \mu \mathrm{mol} / \mathrm{mol}$ apoA-I; oxidized methionine $218-131 \pm 47 \mathrm{mmol} / \mathrm{mol}$ vs. $158 \pm 60 \mathrm{mmol} / \mathrm{mol}$ apoA-I, PBS vs. $\mathrm{AgNO}_{3}, n=4$ ) or plasma of mice fed a HFHSC (chlorinated tyrosine $71-60 \pm 6 \mu \mathrm{mol} / \mathrm{mol}$ vs. $59 \pm 9 \mu \mathrm{mol} / \mathrm{mol}$ apoA-I; oxidized methionine $218-168 \pm 35 \mathrm{mmol} / \mathrm{mol}$ vs. $147 \pm 45 \mathrm{mmol} / \mathrm{mol}$ apoA-I, chow vs. HFHSC, $n=5$ ). These results imply that the oxidation of apoA-I is not a major contributor to the generation of the dysfunctional HDL in these mouse models. To determine whether SAA-containing HDL might be trapped in the adipocyte ECM in vivo, we performed IHC on gonadal ATs from C57BL/6 mice fed either a chow or HFHSC diet for 20 weeks. Chow-fed mice demonstrated little apoA-I, SAA, or ECM staining (blue with Movat's pentachrome stain). Conversely, C57BL/6 mice fed the HFHSC diet demonstrated increased staining for both apoA-I and SAA, which appeared to have a similar pattern of localization with each other and with the ECM (Figure 7B). These findings are consistent with our in vitro observations of SAA-containing HDL binding to the adipocyte cell surface-associated ECM.

To extend our findings to human subjects, we isolated HDL from human subjects with SLE with various degrees of systemic inflammation as assessed by standard inflammatory markers and the SLE Disease Activity Index (SLEDAI; Supplemental Table 1). HDL isolated from 10 healthy human control subjects all inhibited palmitate-induced inflammatory gene expression (data not shown). However, HDL from some SLE patients demonstrated a reduced antiinflammatory effect. Interestingly, the extent of HDL dysfunction as assessed by its inability to inhibit palmitate-induced $S a a 3$ and $C c l 2$ gene expression positively correlated with the level of the circulating inflammatory markers SAA and C-reactive protein (CRP) (Figure 8, A-D). Circulating levels of SAA are a reflection of SAA-HDL, since most SAA is transported in plasma on HDL (24, 25). HDL samples that were most dysfunctional with respect to inhibition of Saa3 and Ccl2 gene expression (i.e., those with high SAA levels) were least able to stimulate cholesterol efflux (Figure 8E). A similar inverse relationship between the ability of HDL to stimulate cholesterol efflux from adipocytes were observed with CRP (Figure 8F) and HDL's inability to inhibit palmitate-induced Saa3 gene expression (Figure 8G). When SLE patients were arbitrarily divided into those with CRP values above and below $10 \mathrm{mg} / \mathrm{l}$, HDL from subjects with the higher CRP values demonstrated a significant loss in its ability to inhibit Saa3 gene expression compared with HDL from subjects with the lower CRP values (Figure $8 \mathrm{H}$ ).

Plasma lipoprotein and lipid concentrations did not correlate with HDL function, as assessed by its ability to inhibit inflammatory gene expression in adipocytes (Supplemental Figure 7A, top 4 panels) - nor did it correlate with cholesterol efflux (Supplemental Fig- ure 7A, bottom 4 panels), plasma SAA (Supplemental Figure 7B, bottom 4 panels), or CRP levels (Supplemental Figure 7B top 4 panels) - indicating that our findings are independent of plasma lipid and lipoprotein levels. Also, there was no significant correlation between the extent of HDL oxidation and its ability to inhibit chemotactic factor gene expression or stimulate cholesterol efflux, nor did the extent of HDL oxidation correlate with the plasma inflammatory markers SAA and CRP (Supplemental Figure 8). These findings imply that inflammatory environments such as seen with obesity in mice or SLE play an important role in impairing the antiinflammatory properties of HDL and that the SAA content of the HDL particle, but not its oxidative status, appears to be operative in vivo.

\section{Discussion}

We previously have shown that HDL from healthy human subjects inhibits palmitate-induced inflammation in differentiated 3T3-L1 adipocytes (16). In the present study, we extend these findings to show that HDL from mice with either severe or modest degrees of systemic inflammation, or HDL from modestly inflamed human subjects, loses some of these antiinflammatory properties. Moreover, this loss of antiinflammatory function relates to the ability of the specific HDL preparation to influence the cholesterol content of LRs in the adipocyte plasma membrane by facilitating cholesterol efflux. In addition, SAA, an HDL apolipoprotein that increases during both acute and chronic inflammation, plays a major role in rendering HDL dysfunctional in both mice and humans.

Our previous studies demonstrated an important role for plasma membrane cholesterol in determining the susceptibility of adipocytes to palmitate-induced inflammation. Strategies that reduced plasma membrane cholesterol - such as preexposure of cells to either HDL from normal healthy human subjects or apoA-I, or exposure to $\mathrm{m} \beta C D$ - were associated with a reduction in the expression of inflammatory genes (16). Conversely, increasing plasma membrane cholesterol by exposure of cells to cholesterol-loaded $\mathrm{m} \beta \mathrm{CD}$ had the opposite effect (16). We also previously showed that changes in membrane cholesterol were accompanied by parallel changes in the generation of ROS and that ROS play an important role in gene expression (16). We now extend these findings to demonstrate that the loss of antiinflammatory properties of various HDL preparations from inflamed mice or humans is less effective at all these functions than control HDL and that these HDL preparations are no longer protective against palmitate-induced inflammation.

Why does the cholesterol content of these plasma membrane domains appear to regulate the inflammatory response in adipocytes? TLR density has been proposed to increase with increased cholesterol content of plasma membranes of macrophages, rendering these cells more susceptible to TLR agonists that are ubiquitous in the environment (54). It is conceivable that similar changes in adipocytes account for the apparent correlation between membrane cholesterol content and inflammatory response, as suggested by our findings in this study. It also is possible that amplification of the innate immune response by a pathway requiring metabolism of saturated fatty acids to ceramide and activation of $\mathrm{PKC}-\zeta /$ mitogen-activated protein kinases is required for these effects, as has been reported in macrophages (55).

Why is the membrane cholesterol content of adipocytes not adequately reduced after exposure of cells to HDL isolated from 
acutely inflamed mice? One possibility relates to the SAA content of HDL under inflammatory conditions. SAA is the major acute-phase reactant in mammals (23). The constitutive form, SAA4, is unaffected by inflammation, while SAA1.1 and SAA2.1 in mice and SAA2 and SAA1 in humans are produced mainly by the liver in response to inflammatory stimuli. SAA also is produced by extrahepatic cells such as adipocytes, macrophages, and enterocytes $(23,56)$. Tissue expression of all inducible forms of SAA increases dramatically in response to acute inflammatory stimuli in both humans and mice, returning to baseline by approximately 72 hours (23). However, in chronic inflammatory states associated with obesity, the metabolic syndrome, and type 2 diabetes, circulating SAA levels are modestly and chronically elevated (57-60). SAA1, -2 , and -4 are transported in plasma mainly bound to $\operatorname{HDL}(24,26,61)$ and are not transported free in plasma. Our data indicate that the presence of SAA in HDL is an important determinant of HDL's ability to suppress inflammation in adipocytes. HDL that was enriched in SAA did not blunt palmitate-induced inflammatory gene expression in our adipocyte assay to the same extent as control HDL. Conversely, HDL isolated from $\mathrm{AgNO}_{3}$-injected mice deficient in both SAA1.1 and SAA2.1 (SAA-DKO mice) had stronger antiinflammatory properties than $\mathrm{HDL}$ from WT $\mathrm{AgNO}_{3}$-injected mice, and HDL isolated several days after the injection of $\mathrm{AgNO}_{3}$ - by which time SAA levels had returned toward normal - functioned like control HDL. These lossand gain-of-function experiments provide strong evidence for an important role of SAA in determining the antiinflammatory properties of HDL, although other factors clearly are involved, as well. It also is unclear why SAA-containing HDL is unable to suppress inflammation to the extent seen with control HDL. One obvious possibility is that SAA-containing HDL is dysfunctional with respect to cholesterol efflux, which would in turn be a major determinant of plasma membrane cholesterol content. Although some studies show that lipid-free SAA can facilitate lipid efflux $(62,63)$ and that the sterol efflux capacity of HDL from hepatocytes improves during inflammation (63), others have shown that SAA-containing HDL inhibits cholesterol efflux and reverse cholesterol transport from macrophages (26-28). Our observations with SAA-depleted and SAA-enriched HDL support the proposal that the SAA content of HDL is an important determinant of its ability to facilitate cholesterol efflux from the plasma membrane of adipocytes.

Important clues to why the presence of SAA on HDL inhibits its ability to adequately facilitate cholesterol efflux are derived from our studies in which we observed colocalization of $\mathrm{HDL}$ from $\mathrm{AgNO}_{3}-$ injected mice and SAA2-HDL with cell surface-associated ECM of adipocytes, whereas normal HDL did not colocalize with the adipocyte cell surface. Colocalization of both these forms of SAA-enriched HDL could be inhibited by prior enzymatic digestion of extracellular proteoglycans, suggesting a critical role for cell surface-associated proteoglycans in these interactions. Moreover, the observation that HDL from inflamed SAA-DKO mice, as well as HDL from inflamed mice in which the positively charged lysine and arginine residues were neutralized, also failed to colocalize with the cell surface of adipocytes invokes a critical role for SAA in the interaction of HDL with proteoglycans associated with the adipocyte cell surface. SAA is well known to have proteoglycan binding domains $(23,49)$. These observations suggest that interaction of SAA on HDL with proteoglycans at the cell surface of adipocytes leads to trapping of the lipoprotein, thus precluding it from adequately interacting with the plasma membrane and facilitating cholesterol efflux. This notion is supported by our findings with respect to the effect of the SAA content on cholesterol efflux from adipocytes, discussed earlier.

Since SAA only accounts for part of the loss of the antiinflammatory effect of HDL, it is of considerable interest to know what other factors might be involved. Since oxidative stress can accompany inflammation $(64,65)$, it is possible that oxidation of apoA-I also accounts in part for the impaired ability of HDL to facilitate efflux. MPO targets apoA-I for site-specific oxidation in human subjects with rheumatoid arthritis (66) and in atherosclerotic lesions (36). Moreover, HDL from atherosclerotic humans have impaired ABCA1-mediated cholesterol efflux and enhanced MPO-mediated apoA-I oxidation (34). Interestingly, the presence of SAA on HDL has been reported to impair HDL's antioxidative functionality (40). However, we were not able to find evidence of oxidized apoA-I in HDL from obese mice with modest degrees of inflammation, nor were we able to find any correlations between measures of HDL oxidation and inhibition of inflammatory gene expression or inflammatory markers in subjects with SLE. These findings suggest that oxidative modification of HDL is not a major contributor to HDL dysfunction under these conditions.

Our findings have potentially important implications for clinical disorders characterized by inflammation, especially those associated with chronic inflammatory states such as SLE, rheumatoid arthritis, obesity, and cardiovascular disease (CVD). McMahon et al. showed that HDL from subjects with rheumatoid arthritis and a large proportion of patients with SLE had a reduced ability to inhibit LDL oxidation, which is a measure of HDL's antiinflammatory potential (22). Since the degree of inflammation varies widely in patients with SLE, we chose to evaluate whether the extent of inflammation in our SLE subjects was a determinant of the ability of HDL to inhibit palmitate-induced inflammation in adipocytes. Our findings indicate that the ability of HDL to inhibit palmitate-induced expression of Saa3 and Ccl2 indeed correlated with circulating levels of CRP and SAA in the SLE patients, both markers of the extent of systemic inflammation. Plasma SAA levels are largely reflective of HDL-SAA levels $(24,25)$. These findings are consistent with our findings using mouse HDL, which indicate an important role for SAA in determining the ability of HDL to exert antiinflammatory functions on adipocytes. They also are consistent with a recent study in which IL-6 receptor blockade in patients with rheumatoid arthritis resulted in marked reduction in CRP, which was accompanied by a parallel reduction in the content of SAA-containing HDL, without a change in HDL-cholesterol levels (67). Thus, SAA-HDL might be a useful biomarker for the antiinflammatory properties of HDL. Other conditions in which HDL is likely to be dysfunctional are the metabolic syndrome and type 2 diabetes, both of which are characterized by low HDL cholesterol levels and systemic inflammation. SLE subjects with high CRP values had substantially higher BMIs than those with lower CRP values. Therefore, we cannot exclude the possibility that obesity contributed to the HDL dysfunction in this group of patients. It also is conceivable that the inability of HDL to suppress inflammation in AT could lead the production of additional cytokines by AT, thereby fueling a cycle in which some of the deleterious effects of inflammation could be propagated, thus playing a causal role in the inflammation associated with the metabolic syndrome. Future stud- 
ies that investigate the relationships among obesity, inflammation, and HDL function are likely to provide additional insights into the importance of HDL as a cardioprotective and antiinflammatory lipoprotein. Strategies to inhibit such a cycle has obvious translational implications for the management of chronic inflammatory disorders such as SLE, rheumatoid arthritis, the metabolic syndrome, and type 2 diabetes - disorders in which inflammation has been suggested to play a role in the pathogenesis of CVD.

It is possible that the negative results of recent clinical trials in which drug-induced increases in HDL-cholesterol did not result in improved clinical outcomes (68-70) might relate to HDL-cholesterol being the wrong metric by which to assess HDL. For example, recent studies suggest that HDL-mediated sterol efflux from macrophages is a better marker of CVD risk than HDL-cholesterol (71, 72). Future clinical studies should include the antiinflammatory capacity of HDL. Moreover, new biomarkers such as SAA-HDL, which reflects HDL function, may prove to be better metrics of CVD risk than HDL-cholesterol per se.

\section{Methods}

Reagents. Palmitate (16:0) (Sigma-Aldrich) was conjugated with albumin, as described previously (73). Briefly, palmitate was first dissolved in $\mathrm{NaOH}(100 \mathrm{mmol} / \mathrm{l})$ to a final concentration of $100 \mathrm{mmol} / \mathrm{l}$, and conjugated with fatty acid-free albumin (Sigma-Aldrich) at a molar ration of 3:1 (palmitate/albumin). Alexa Fluor 594-conjugated CTB was purchased from Invitrogen. HDL $(\mathrm{d}=1.063-1.210 \mathrm{~g} / \mathrm{ml})$ was isolated from plasma of mice, healthy human volunteers, and SLE patients by ultracentrifugation $(45,74)$. Human apoA-I was purchased from Academy Bio-medical Co. Murine and human SAA protein concentrations were measured by ELISA kits (Immunology Consultants Laboratory Inc.). Anti-GAPDH antibody was purchased from Cell Signaling Technology (5174S, 1:1,000).

Animals, diets, and human subjects. To determine whether acute inflammation influenced HDL's ability to inhibit palmitate-induced expression of chemotactic factors in adipocytes, 10-week-old male C57BL/6 mice or SAA-DKO mice (43) were i.p. injected with $\mathrm{AgNO}_{3}$ $(0.5 \mathrm{ml}, 0.015 \mathrm{mg} / \mathrm{ml})$ or PBS. After 24 hours, plasma was obtained for isolation of HDL by ultracentrifugation $(45,74)$. To determine the effect of more moderate chronic inflammation on HDL function, HDL was isolated from mice that had been made obese by consumption of an obesogenic, proinflammatory diet. For this purpose, 10-week-old male LDL receptor-deficient ( $\mathrm{Ldlr}^{-/-}$) mice on a C57BL/6 background or WT C57BL/6 mice were fed a HFHSC diet (35.5\% calories as fat and $36.6 \%$ as carbohydrate, $0.15 \%$ added cholesterol; F4997, BioServ) for 20 weeks, which resulted in obesity, insulin resistance, and both AT and systemic inflammation (75). Chow-fed $\mathrm{Ldlr}^{--}$or C57BL/6 mice were used as controls. SAA-DKO, $\mathrm{Ldlr}^{--}$, and some C57BL/6 mice were from an in-house breeding colony. Other C57BL/6 mice were purchased from The Jackson Laboratory. At sacrifice, HDL was isolated from plasma by ultracentrifugation. HDL particle concentration was measured by calibrated ion mobility analysis (76).

To test whether HDL from human subjects with chronic inflammation was dysfunctional, HDL was isolated from 18 subjects with SLE recruited from outpatient clinics at the University of Washington Hospital and Harborview Medical Center. All met the American College of Rheumatology's criteria for this diagnosis. From a cohort of SLE patients, we randomly selected 8 patients with high CRP and
10 with low CRP. Plasma samples were stored in aliquots at $-80^{\circ} \mathrm{C}$. Plasma lipid and lipoprotein levels were measured enzymatically in the core laboratories of the University of Washington's Nutrition Obesity Research Center, and free cholesterol and total phospholipid were measured enzymatically in the University of Washington's Northwest Lipid Metabolism and Diabetes Research Laboratories.

Adipocyte cell culture and RT-PCR. 3T3-L1 murine preadipocytes, obtained from the American Type Tissue Culture Collection, and MEFs, isolated from embryos of C57BL/6 mice at 13.5 days postcoitum (a gift from Carol B. Ware, University of Washington), were propagated and differentiated according to standard procedures (77). Human SGBS (a gift from Martin Wabitsch, University of Ulm, Ulm, Germany) were grown and differentiated as described previously (42). Fully differentiated adipocytes were pretreated with $50 \mu \mathrm{g}$ protein $/ \mathrm{ml}$ or the indicated concentration of HDL protein or apoA-I for 6 hours, and then washed 3 times with PBS. Adipocytes then were incubated for 24 hours with $250 \mu \mathrm{mol} / \mathrm{l}$ palmitate for measurement of gene expression by reverse transcription PCR (RT-PCR). RT-PCR was performed using the TaqMan Master kit (Applied Biosystems) in the ABI prism 7900HT system (75, 78). Saa3, Ccl2, Il1, Il6, and Gapdh primers with FAM probes were obtained from Applied Biosystems (Assayon-Demand). Each sample was analyzed in triplicate and normalized using GAPDH as control. Some samples also were normalized with a second housekeeping gene, $\beta$-2-microglobulin (B2m) and showed similar results (Supplemental Figure 9).

Cholesterol efflux from adipocytes. To measure the cholesterol efflux capacity of HDL, fully differentiated 3T3-L1 adipocytes were radiolabeled by incubating the cells with $1 \mu \mathrm{Ci} / \mathrm{ml}{ }^{3} \mathrm{H}$-cholesterol (PerkinElmer) in DMEM/1 mg/ml fatty acid-free BSA overnight. Cells were then washed and incubated with DMEM/fatty acid-free BSA without or with $50 \mu \mathrm{g}$ protein $/ \mathrm{ml}$ or the indicated concentration of HDL protein for 6 hours at $37^{\circ} \mathrm{C}$. Medium was collected and filtered, and the ${ }^{3} \mathrm{H}$-cholesterol content of medium and cells was quantified. The fraction of total ${ }^{3} \mathrm{H}$-cholesterol released into the medium was calculated as (counts in the medium with HDL - counts in the medium without HDL) /(counts in the medium + counts in the cells $) \times 100$.

Measurement of plasma membrane cholesterol and LRs. Cellular membranes were isolated from 3T3-L1 adipocytes as described previously (79). Membrane preparations were resuspended in $100 \mu \mathrm{l}$ of ethanolic potassium hydroxide $(1 \mathrm{~mol} / \mathrm{l})$, and cholesterol-d7 was added as the internal standard. After saponification, the lipid fraction was extracted from the membrane preparations with hexane and dried under nitrogen gas. Total cholesterol levels were determined after derivatization using liquid chromatography electrospray ionization tandem MS (LC-MS/MS), as described previously $(16,80)$.

LRs in plasma membranes of 3T3-L1 adipocytes were quantified as described previously (79) using Alexa Fluor 594-conjugated CTB (Molecular Probes, Invitrogen). Briefly, cultured 3T3-L1 adipocytes were incubated with $1 \mu \mathrm{g} / \mathrm{ml}$ of Alexa Fluor 594-conjugated CTB for 15 minutes at $4^{\circ} \mathrm{C}$. After washing twice with cold PBS, cells were fixed in $4 \%$ paraformaldehyde for 20 minutes at $4^{\circ} \mathrm{C}$. CTB staining of fixed cells was analyzed by FACS (FACSCanto, BD Biosciences), as described previously (16).

Detergent-free LR fractionation. LR and non-LR fractions from adipocytes were obtained by OptiPrep (Sigma-Aldrich) gradient centrifugation using a detergent-free protocol, as described previously (79). Briefly, the cell pellet was homogenized in buffer (250 
$\mathrm{mmol} / \mathrm{l}$ sucrose, $1 \mathrm{mmol} / \mathrm{l} \mathrm{EDTA}, 500 \mathrm{mmol} / \mathrm{l}$ sodium bicarbonate, $\mathrm{pH}$ 11). After centrifugation $(1,000 \times g, 10$ minutes), the postnuclear supernatant fraction was added to $60 \%$ OptiPrep to make $35 \%$ OptiPrep (final concentration), overlaid on a discontinuous gradient of 5\%-35\% OptiPrep and centrifuged at 350,000 $\mathrm{g}$ in a Beckman NVT 65.2 rotor for 90 minutes at $4^{\circ} \mathrm{C}$. Nine $0.5-\mathrm{ml}$ fractions were collected and subjected to immunoblotting using antibodies against TLR4 (Cell Signaling Technology, 14358; 1:1,000) and caveolin-1 (Cell Signaling Technology, 3238; 1:1,000). To evaluate the specificity of the TLR4 antibody, immunoblot analysis was performed using fat pads from TLR4-deficient mice and control mice (Supplemental Figure 10). This antibody nicely detected TLR4 protein in AT from control but not TLR4-deficient mice.

Quantification of ROS. ROS generation by adipocytes was assessed as $\mathrm{CM}-\mathrm{H}_{2} \mathrm{DCFDA}$ (Molecular Probes, Invitrogen) fluorescence, which was monitored by FACS (FACSCanto, BD Biosciences), as described previously $(73,79)$.

Quantification of oxidative modification in HDL by MS. HDL isolated by sequential ultracentrifugation from control mice, $\mathrm{AgNO}_{3}$-injected mice, mice fed a HFHSC diet, and from healthy subjects or SLE patients was supplemented with $100 \mu \mathrm{mol} / \mathrm{l}$ diethylenetriaminepentaacetic acid, $100 \mu \mathrm{mol} / \mathrm{l}$ butylated hydroxytoluene, and a protease inhibitor cocktail (Sigma-Aldrich) to inhibit artifactual oxidation during isolation. An aliquot (10 $\mu \mathrm{g}$ protein) of HDL was reduced with dithiothreitol (DTT), alkylated with iodoacetamide, and then digested with trypsin and Glu-C as previously described (81). HDL digests was analyzed by nano-LC/selected reaction monitoring-MS/MS (nano-LC/SRM-MS/ MS) on a Thermo TSQ Vantage coupled to a Waters nanoACQUITY UltraPerformance liquid chromatography (nano-UPLC) system for quantification of methionine and tryptophan oxidation in apoA-I as described previously $(34,36)$. The same approach was applied to quantify the levels of chlorinated Tyr192 and oxidized Met148 in human HDL isolated from healthy subjects and SLE patients (34).

Preparation of SAA-enriched HDL. To make SAA-enriched HDL, we first transduced lentivirus-encoding mouse SAA2.1 under the cytomegalovirus (CMV) promoter into HEK 293 cells. After confirming stable transduction using GFP protein, human HDL was added to either SAA2.1-transduced or mock-transduced cells at a final concentration of $0.3 \mathrm{mg} / \mathrm{ml}$. Twenty-four hours later, conditioned media were collected and the HDL was reisolated by ultracentrifugation. We generated 3 different types of reconstituted HDL; SAA2-HDL indicates reisolated HDL with conditioned media from cells transduced by lentivirus encoding SAA2.1 protein; mock-HDL indicates reisolated HDL exposed to cells transduced by mock lentivirus; and control-HDL represents HDL reisolated from conditioned media from cells not transduced with lentivirus.

Chemical modification of HDL. Selective chemical modification of lysine and arginine residues in HDL was performed as described previously for LDL (82-84). Cyclohexanedione was used to modify arginine residues and reductive methylation for lysine modification. Briefly, $\mathrm{HDL}$ from $\mathrm{AgNO}_{3}$-injected C57BL/6 mice $(1 \mathrm{mg} / \mathrm{ml})$ was dialyzed in $0.1 \mathrm{~mol} / \mathrm{l}$ sodium borate buffer $(\mathrm{pH} 8.1)$ and incubated with $0.15 \mathrm{~mol} / 1$ 1,2-cyclohexadione (Sigma-Aldrich) in 0.1 mol/l sodium borate buffer ( $\mathrm{pH} 8.1$ ) at $37^{\circ} \mathrm{C}$ for 2 hours. Modified HDL was then dialyzed in $0.1 \mathrm{~mol} / 1$ sodium borate buffer ( $\mathrm{pH} 9.0$ ) for reductive methylation. The procedure was performed on ice as follows: $1 \mathrm{mg}$ of sodium borohydride (Sigma-Aldrich) and $5 \mu \mathrm{l}$ of
7.4\% formaldehyde (Sigma-Aldrich) were added to $1 \mathrm{mg} / \mathrm{ml}$ of HDL. Additional $5 \mu \mathrm{l}$ aliquots of $7.4 \%$ formaldehyde were added every 6 minutes for 30 minutes. For a more extensive modification, another $1 \mathrm{mg}$ of sodium borohydride was added after 30 minutes, and additions of formaldehyde were continued at 6-minute intervals for a total 60 minutes. The reaction was stopped by dialysis against 0.15 mol/1 NaCl, 0.01\%EDTA, pH 7.0.

Immunofluorescence and IHC. DiI-labeled HDL was generated by incubation of HDL with the red dye, DiI (Molecular Probes, Invitrogen). Briefly, $300 \mu \mathrm{l}$ of DiI in dimethyl sulfoxide $(3 \mathrm{mg} / \mathrm{ml})$ was added slowly to $5 \mathrm{ml} \mathrm{HDL} \mathrm{(2} \mathrm{mg}$ protein/ml) in $0.1 \mathrm{M}$ phosphate-buffered saline, $\mathrm{pH}$ 7.4. The mixture was agitated gently and incubated for 8 hours at $37^{\circ} \mathrm{C}$ under nitrogen in the dark. DiI-labeled HDL was reisolated by ultracentrifugation $(\mathrm{d}=1.063-1.21 \mathrm{~g} / \mathrm{ml})$.

To evaluate the localization of DiI and the ECM in adipocytes, 3T3-L1 adipocytes were cultured on glass cover slips, and DiI-labeled HDL preparations were added for 6 hours, then fixed in $2 \%$ formalin for 5 minutes. The ECM of adipocytes was stained using a cell-impermeable Alexa Fluor 594-conjugated WGA (Molecular Probes, Invitrogen), which selectively binds to $\mathrm{N}$-acetylglucosamine and $\mathrm{N}$-acetylneuraminic acid residues on plasma membranes (85). For some experiments, the ECM was digested prior to adding DiI-labeled HDL by incubation of the cells with chondroitin ABC lyase (Proteus vulgaris, Seikagaku Corp.) (0.1 unit/ml) in $0.1 \mathrm{M}$ Tris, $0.1 \mathrm{M}$ acetate ( $\mathrm{pH} 7.3$ ), and heparitinase (Flauobacterium heparinum, Seikagaku Corp.) (10 mU/ $\mathrm{ml}$ ) for 1 hour at $37^{\circ} \mathrm{C}$. To determine whether DiI-labeled HDL binds to hyaluronan produced by 3T3-L1 adipocytes (51), the cellassociated ECM was digested prior to adding HDL by incubation with Streptomyces hyaluronidase (200 mU/ml, Sigma-Aldrich) for 1 hour at $37^{\circ} \mathrm{C}$. Nuclei were counterstained with DAPI. Cells were photographed using an Axioskop fluorescent microscope (Zeiss).

For IHC, ATs were fixed in $10 \%$ formalin for immunohistochemical staining with apoA-I (Rockland Immunochemicals, 600-101-196, 1:4000) or SAA (R\&D Systems, AF2948, 1:25) antibodies, as described previously (86). Images were morphometrically analyzed using Image Pro Plus 6.0 (Media Cybernetics).

Statistics. Statistical significance was determined with SPSS (Windows version 19) or OriginPro software (version 8.6; Origin Laboratory). All data are shown as means \pm SD of 3 independent experiments performed in triplicate. Student $t$ test was used to detect differences within groups when applicable (2-tailed and unpaired). One-way ANOVA was used to compare differences among all groups, and Bonferroni post-hoc testing was used to detect differences among mean values of the groups. Pearson coefficient was used for linear regression analysis. $P<0.05$ was considered significant.

Study approval. All experimental procedures in mice were undertaken with approval from the Institutional Animal Care and Use Committee of the University of Washington (protocol nos. 3104-01 and 4237-01).

All human subjects provided written informed consent and authorization for blood draws and release of medical information (protocol no. 39712).

\section{Author contributions}

CYH, CT, HW, TW, BS, SS, MO, SW, KDO, SMM, TNW, TV, MCD, FCD, and WRO conducted experiments. MCD, FCD, MEG, and 
$\mathrm{KBE}$ contributed essential reagents or tools. All authors interpreted the data. CYH, MCD, FCD, and AC supervised the work, interpreted the data, and wrote the manuscript.

\section{Acknowledgments}

This work was supported in part by NIH grants HL092969, 094352, and DK-035816 and a Beginning Grant-in-Aid from the
American Heart Association (to C.Y. Han). A. Chait was supported by a Grant-in-Aid from the American Heart Association.

Address correspondence to: Alan Chait, Division of Metabolism, Endocrinology and Nutrition, Box 356426, University of Washington, Seattle, Washington 98195-6426, USA. Phone: 206.543.3158; E-mail: achait@u.washington.edu.
1. Rashid S, Genest J. Effect of obesity on high-density lipoprotein metabolism. Obesity (Silver Spring). 2007;15(12):2875-2888.

2. Grundy SM. Cardiovascular and metabolic risk factors: how can we improve outcomes in the highrisk patient? Am JMed. 2007;120(9 suppl 1):S3-S8.

3. Hardy OT, Czech MP, Corvera S. What causes the insulin resistance underlying obesity? Curr Opin Endocrinol Diabetes Obes. 2012;19(2):81-87.

4. Schmidt AM. Insulin resistance and metabolic syndrome: mechanisms and consequences. Arterioscler Thromb Vasc Biol. 2012;32(8):1753.

5. Calabro P, Yeh ET. Intra-abdominal adiposity, inflammation, and cardiovascular risk: new insight into global cardiometabolic risk. Curr Hypertens Rep. 2008;10(1):32-38.

6. Khovidhunkit W, et al. Effects of infection and inflammation on lipid and lipoprotein metabolism: mechanisms and consequences to the host. JLipid Res. 2004;45(7):1169-1196.

7. Alwaili K, Awan Z, Alshahrani A, Genest J. High-density lipoproteins and cardiovascular disease: 2010 update. Expert Rev Cardiovasc Ther. 2010;8(3):413-423.

8. Barter PJ, Nicholls S, Rye KA, Anantharamaiah GM, Navab M, Fogelman AM. Antiinflammatory properties of HDL. Circ Res. 2004;95(8):764-772.

9. Barter PJ, Puranik R, Rye KA. New insights into the role of HDL as an anti-inflammatory agent in the prevention of cardiovascular disease. Curr Cardiol Rep. 2007;9(6):493-498.

10. Murphy AJ, et al. High-density lipoprotein reduces the human monocyte inflammatory response. Arterioscler Thromb Vasc Biol. 2008;28(11):2071-2077.

11. Sun Y, et al. Free cholesterol accumulation in macrophage membranes activates Toll-like receptors and $\mathrm{p} 38$ mitogen-activated protein kinase and induces cathepsin K. Circ Res. 2009;104(4):455-465.

12. Kunitake ST, Jarvis MR, Hamilton RL, Kane JP. Binding of transition metals by apolipoprotein A-I-containing plasma lipoproteins: inhibition of oxidation of low density lipoproteins. Proc Natl Acad Sci U S A. 1992;89(15):6993-6997.

13. Parthasarathy S, Barnett J, Fong LG. High-density lipoprotein inhibits the oxidative modification of low-density lipoprotein. Biochim Biophys Acta. 1990;1044(2):275-283.

14. Cockerill GW, Rye KA, Gamble JR, Vadas MA, Barter PJ. High-density lipoproteins inhibit cytokine-induced expression of endothelial cell adhesion molecules. Arterioscler Thromb Vasc Biol. 1995;15(11):1987-1994.

15. Nicholls SJ, et al. Reconstituted high-density lipoproteins inhibit the acute pro-oxidant and proinflammatory vascular changes induced by a periarterial collar in normocholesterolemic rab- bits. Circulation. 2005;111(12):1543-1550.

16. Umemoto T, et al. Apolipoprotein AI and high-density lipoprotein have anti-inflammatory effects on adipocytes via cholesterol transporters: ATP-binding cassette A-1, ATP binding cassette G-1, and scavenger receptor B-1. Circ Res. 2013;112(10):1345-1354.

17. Ansell BJ, Fonarow GC, Fogelman AM. High-density lipoprotein: is it always atheroprotective? Curr Atheroscler Rep. 2006;8(5):405-411.

18. Ansell BJ, Fonarow GC, Fogelman AM. The paradox of dysfunctional high-density lipoprotein. Curr Opin Lipidol. 2007;18(4):427-434.

19. Ansell BJ, et al. Inflammatory/antiinflammatory properties of high-density lipoprotein distinguish patients from control subjects better than high-density lipoprotein cholesterol levels and are favorably affected by simvastatin treatment. Circulation. 2003;108(22):2751-2756.

20. Van Lenten BJ, Wagner AC, Nayak DP, Hama S, Navab M, Fogelman AM. High-density lipoprotein loses its anti-inflammatory properties during acute influenza a infection. Circulation. 2001;103(18):2283-2288.

21. Van Lenten BJ, et al. Anti-inflammatory HDL becomes pro-inflammatory during the acute phase response. Loss of protective effect of HDL against LDL oxidation in aortic wall cell cocultures. JClin Invest. 1995;96(6):2758-2767.

22. McMahon M, et al. Proinflammatory high-density lipoprotein as a biomarker for atherosclerosis in patients with systemic lupus erythematosus and rheumatoid arthritis. Arthritis Rheum. 2006;54(8):2541-2549.

23. Uhlar CM, Whitehead AS. Serum amyloid A, the major vertebrate acute-phase reactant. Eur J Biochem. 1999;265(2):501-523.

24. van der Westhuyzen DR, de Beer FC, Webb NR. HDL cholesterol transport during inflammation. Curr Opin Lipidol. 2007;18(2):147-151.

25. Coetzee GA, Strachan AF, van der Westhuyzen DR, Hoppe HC, Jeenah MS, de Beer FC. Serum amyloid A-containing human high density lipoprotein 3. Density, size, and apolipoprotein composition. J Biol Chem. 1986;261(21):9644-9651.

26. Artl A, Marsche G, Lestavel S, Sattler W, Malle E. Role of serum amyloid A during metabolism of acute-phase HDL by macrophages. Arterioscler Thromb Vasc Biol. 2000;20(3):763-772.

27. Banka CL, Yuan T, de Beer MC, Kindy M, Curtiss LK, de Beer FC. Serum amyloid A (SAA): influence on HDL-mediated cellular cholesterol efflux. J Lipid Res. 1995;36(5):1058-1065.

28. Tsun JG, Shiu SW, Wong Y, Yung S, Chan TM, Tan KC. Impact of serum amyloid A on cellular cholesterol efflux to serum in type 2 diabetes mellitus. Atherosclerosis. 2013;231(2):405-410.

29. Vaisar T, et al. Inflammatory remodeling of the
HDL proteome impairs cholesterol efflux capacity. J Lipid Res. 2015;56(8):1519-1530.

30. Tolle M, et al. High-density lipoprotein loses its anti-inflammatory capacity by accumulation of pro-inflammatory-serum amyloid A. Cardiovasc Res. 2012;94(1):154-162.

31. Shao B, et al. Tyrosine 192 in apolipoprotein A-I is the major site of nitration and chlorination by myeloperoxidase, but only chlorination markedly impairs ABCA1-dependent cholesterol transport. J Biol Chem. 2005;280(7):5983-5993.

32. Shao B, Oda MN, Oram JF, Heinecke JW. Myeloperoxidase: an oxidative pathway for generating dysfunctional high-density lipoprotein. Chem Res Toxicol. 2010;23(3):447-454.

33. Shao B, Tang C, Heinecke JW, Oram JF. Oxidation of apolipoprotein A-I by myeloperoxidase impairs the initial interactions with ABCA1 required for signaling and cholesterol export. JLipid Res. 2010;51(7):1849-1858.

34. Shao B, et al. Humans with atherosclerosis have impaired ABCA1 cholesterol efflux enhanced HDL oxidation by myeloperoxidase. Circ Res. 2014;114(11):1733-1742.

35. Pennathur $\mathrm{S}$, et al. Human atherosclerotic intima and blood of patients with established coronary artery disease contain high density lipoprotein damaged by reactive nitrogen species. J Biol Chem. 2004;279(41):42977-42983.

36. Shao B, Pennathur S, Heinecke JW. Myeloperoxidase targets apolipoprotein A-I, the major high density lipoprotein protein, for site-specific oxidation in human atherosclerotic lesions. J Biol Chem. 2012;287(9):6375-6386.

37. Park S, Park NY, Valacchi G, Lim Y. Calorie restriction with a high-fat diet effectively attenuated inflammatory response and oxidative stress-related markers in obese tissues of the high diet fed rats. Mediators Inflamm. 2012;2012:984643.

38. Alemany M. Regulation of adipose tissue energy availability through blood flow control in the metabolic syndrome. Free Radic Biol Med. 2012;52(10):2108-2119.

39. Das SK, et al. An integrative genomics approach identifies activation of thioredoxin/thioredoxin reductase-1-mediated oxidative stress defense pathway and inhibition of angiogenesis in obese nondiabetic human subjects. JClin Endocrinol Metab. 2011;96(8):E1308-E1313.

40. Dullaart RP, de Boer JF, Annema W, Tietge UJ. The inverse relation of HDL anti-oxidative functionality with serum amyloid A is lost in metabolic syndrome subjects. Obesity (Silver Spring). 2013;21(2):361-366.

41. Harder T, Scheiffele P, Verkade P, Simons K. Lipid domain structure of the plasma membrane revealed by patching of membrane components. 
JCell Biol. 1998;141(4):929-942.

42. Wabitsch M, et al. Characterization of a human preadipocyte cell strain with high capacity for adipose differentiation. Int JObes Relat Metab Disord. 2001;25(1):8-15.

43. De Beer MC, et al. Deficiency of endogenous acute phase serum amyloid A does not affect atherosclerotic lesions in apolipoprotein Edeficient mice. Arterioscler Thromb Vasc Biol. 2014;34(2):255-261.

44. Kim MH, de Beer MC, Wroblewski JM, Webb NR, de Beer FC. SAA does not induce cytokine production in physiological conditions. Cytokine. 2013;61(2):506-512.

45. de Beer MC, et al. Impact of serum amyloid A on high density lipoprotein composition and levels. JLipid Res. 2010;51(11):3117-3125.

46. Lee JY, Sohn KH, Rhee SH, Hwang D. Saturated fatty acids, but not unsaturated fatty acids, induce the expression of cyclooxygenase- 2 mediated through Toll-like receptor 4. J Biol Chem. 2001;276(20):16683-16689.

47. Lee JY, et al. Differential modulation of Toll-like receptors by fatty acids: preferential inhibition by $\mathrm{n}-3$ polyunsaturated fatty acids. J Lipid Res. 2003;44(3):479-486.

48. Wong SW, Kwon MJ, Choi AM, Kim HP, Nakahira $\mathrm{K}$, Hwang DH. Fatty acids modulate Toll-like receptor 4 activation through regulation of receptor dimerization and recruitment into lipid rafts in a reactive oxygen species-dependent manner. J Biol Chem. 2009;284(40):27384-27392 .

49. Chiba T, et al. Serum amyloid A facilitates the binding of high-density lipoprotein from mice injected with lipopolysaccharide to vascular proteoglycans. Arterioscler Thromb Vasc Biol. 2011;31(6):1326-1332.

50. O'Brien KD, et al. Comparison of apolipoprotein and proteoglycan deposits in human coronary atherosclerotic plaques: colocalization of biglycan with apolipoproteins. Circulation . 1998;98(6):519-527.

51. Han CY, et al. Adipocyte-derived serum amyloid A3 and hyaluronan play a role in monocyte recruitment and adhesion. Diabetes. 2007;56(9):2260-2273.

52. Rosenson RS, et al. Cholesterol efflux and atheroprotection: advancing the concept of reverse cholesterol transport. Circulation. 2012;125(15):1905-1919.

53. Dagher G, Donne N, Klein C, Ferre P, Dugail I. HDL-mediated cholesterol uptake and targeting to lipid droplets in adipocytes. J Lipid Res. 2003;44(10):1811-1820.

54. Yvan-Charvet L, et al. Increased inflammatory gene expression in $\mathrm{ABC}$ transporter-deficient macrophages: free cholesterol accumulation, increased signaling via toll-like receptors, and neutrophil infiltration of atherosclerotic lesions. Circulation. 2008;118(18):1837-1847.

55. Schwartz EA, et al. Nutrient modification of the innate immune response: a novel mechanism by which saturated fatty acids greatly amplify monocyte inflammation. Arterioscler Thromb Vasc Biol. 2010;30(4):802-808.
56. Ivanov II, et al. Induction of intestinal Th17 cells by segmented filamentous bacteria. Cell. 2009;139(3):485-498.

57. Ridker PM, Hennekens CH, Buring JE, Rifai N. C-reactive protein and other markers of inflammation in the prediction of cardiovascular disease in women. $N$ Engl J Med. 2000;342(12):836-843.

58. Kip KE, et al. Global inflammation predicts cardiovascular risk in women: a report from the Women's Ischemia Syndrome Evaluation (WISE) study. Am Heart J. 2005;150(5):900-906.

59. Ogasawara K, et al. A serum amyloid A and LDL complex as a new prognostic marker in stable coronary artery disease. Atherosclerosis. 2004;174(2):349-356.

60. Johnson BD, et al. Serum amyloid A as a predictor of coronary artery disease and cardiovascular outcome in women: the National Heart, Lung, and Blood Institute-Sponsored Women's Ischemia Syndrome Evaluation (WISE). Circulation. 2004;109(6):726-732.

61. King VL, Thompson J, Tannock LR. Serum amyloid A in atherosclerosis. Curr Opin Lipidol. 2011;22(4):302-307.

62. Stonik JA, Remaley AT, Demosky SJ, Neufeld EB, Bocharov A, Brewer HB. Serum amyloid A promotes ABCA1-dependent and ABCA1-independent lipid efflux from cells. Biochem Biophys Res Commun. 2004;321(4):936-941.

63. van der Westhuyzen DR, Cai L, de Beer MC, de Beer FC. Serum amyloid A promotes cholesterol efflux mediated by scavenger receptor B-I. J Biol Chem. 2005;280(43):35890-35895.

64. Khansari N, Shakiba Y, Mahmoudi M. Chronic inflammation and oxidative stress as a major cause of age-related diseases and cancer. Recent Pat Inflamm Allergy Drug Discov. 2009;3(1):73-80.

65. Pashkow FJ. Oxidative stress and inflammation in heart disease: do antioxidants have a role in treatment and/or prevention? Int J Inflam. 2011;2011:514623.

66. Vivekanandan-Giri A, et al. High density lipoprotein is targeted for oxidation by myeloperoxidase in rheumatoid arthritis. Ann Rheum Dis. 2013;72(10):1725-1731.

67. McInnes IB, et al. Effect of interleukin-6 receptor blockade on surrogates of vascular risk in rheumatoid arthritis: MEASURE, a randomised, placebo-controlled study. Ann Rheum Dis. 2013;74(4):694-702.

68. Vergeer M, Holleboom AG, Kastelein JJ, Kuivenhoven JA. The HDL hypothesis: does high-density lipoprotein protect from atherosclerosis? JLipid Res. 2010;51(8):2058-2073.

69. Heinecke JW. The not-so-simple HDL story: A new era for quantifying HDL and cardiovascular risk? Nat Med. 2012;18(9):1346-1347.

70. Rader DJ, Tall AR. The not-so-simple HDL story: Is it time to revise the HDL cholesterol hypothesis? Nat Med. 2012;18(9):1344-1346.

71. Khera AV, et al. Cholesterol efflux capacity, high-density lipoprotein function, and atherosclerosis. N Engl J Med.2011;364(2):127-135.
72. Rohatgi A, et al. HDL cholesterol efflux capacity and incident cardiovascular events. N Engl J Med. 2014;371(25):2383-2393.

73. Han CY, et al. Differential effect of saturated and unsaturated free fatty acids on the generation of monocyte adhesion and chemotactic factors by adipocytes: dissociation of adipocyte hypertrophy from inflammation. Diabetes. 2010;59(2):386-396.

74. Webb NR, et al. Adenoviral vector-mediated overexpression of serum amyloid A in apoA-Ideficient mice. J Lipid Res. 1997;38(8):1583-1590.

75. Subramanian S, et al. Dietary cholesterol worsens adipose tissue macrophage accumulation and atherosclerosis in obese LDL receptordeficient mice. Arterioscler Thromb Vasc Biol. 2008;28(4):685-691.

76. Hutchins PM, et al. Quantification of HDL particle concentration by calibrated ion mobility analysis. Clin Chem. 2014;60(11):1393-1401.

77. Lin Y, et al. The hyperglycemia-induced inflammatory response in adipocytes: the role of reactive oxygen species. J Biol Chem. 2005;280(6):4617-4626.

78. Han CY, et al. Reciprocal and coordinate regulation of serum amyloid A versus apolipoprotein A-I and paraoxonase- 1 by inflammation in murine hepatocytes. Arterioscler Thromb Vasc Biol. 2006;26(8):1806-1813.

79. Han CY, et al. NADPH oxidase-derived reactive oxygen species increases expression of monocyte chemotactic factor genes in cultured adipocytes. J Biol Chem. 2012;287(13):10379-10393.

80. Honda A, et al. Highly sensitive quantification of key regulatory oxysterols in biological samples by LC-ESI-MS/MS. J Lipid Res. 2009;50(2):350-357.

81. Shao B, Heinecke JW. Using tandem mass spectrometry to quantify site-specific chlorination and nitration of proteins: model system studies with high-density lipoprotein oxidized by myeloperoxidase. Methods Enzymol. 2008;440:33-63.

82. Weisgraber KH, Innerarity TL, Mahley RW. Role of lysine residues of plasma lipoproteins in high affinity binding to cell surface receptors on human fibroblasts. J Biol Chem. 1978;253(24):9053-9062.

83. Innerarity TL, Pitas RE, Mahley RW. Lipoprotein-receptor interactions. In: Albers JJ, Segrest JP, eds. Plasma Lipoproteins. San Diego, California, USA: Academic Press; 1986.

84. Mahley RW, Innerarity TL, Pitas RE, Weisgraber KH, Brown JH, Gross E. Inhibition of lipoprotein binding to cell surface receptors of fibroblasts following selective modification of arginyl residues in arginine-rich and B apoproteins. J Biol Chem. 1977;252(20):7279-7287.

85. Ohno J, Tajima Y, Utsumi N. Binding of wheat germ agglutinin in the matrix of rat tracheal cartilage. Histochem J. 1986;18(10):537-540.

86. O'Brien KD, et al. Serum amyloid A and lipoprotein retention in murine models of atherosclerosis. Arterioscler Thromb Vasc Biol. 2005;25(4):785-790. 